\title{
Sound Theaters of the 21st Century: Material Functions and Voltaic Performativities
}

\author{
edited by Gail Priest
}

- Robin Fox and Tamara Saulwick interviewed by Gail Priest, Sounding Digital Consciousness: Robin Fox \& Chamber Made's Diaspora, pp. 142-153

- Cat Hope, Opera Activism: Speechless-An Animated Notation Opera for Every Musician, pp. 154-163

- Matthew Sergeant, Performing Installations: An Interview with Kathy Hinde, pp. 164-171

- Christophe Charles, Elements of Performativity in the Works of Kosugi Takehisa and Kazakura Shō, pp. 172-183

- Scott Gibbons, From Notes and Correspondences Regarding BUSTER, Initiating Bros (A Practice-Based Account of Work with Romeo Castellucci and Societas), pp. 184-190

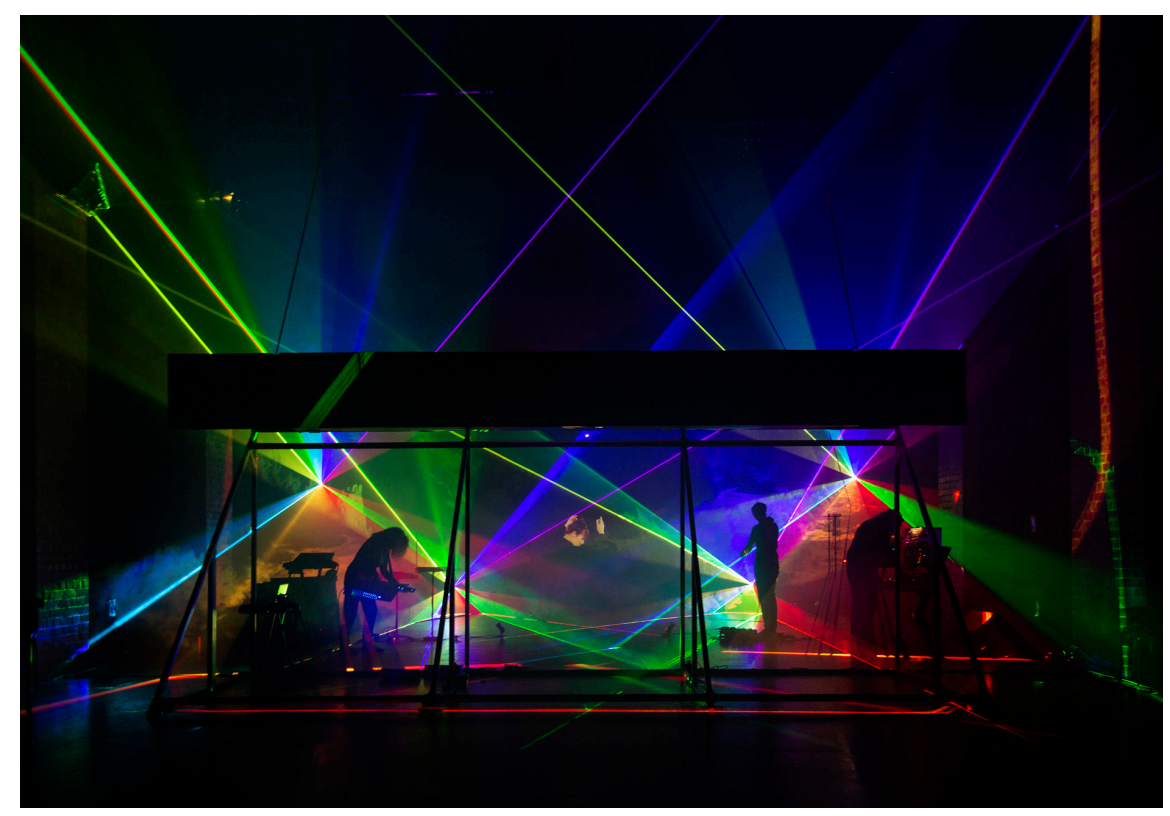

Madeleine Flynn, Georgina Darvidis, Erkki Veltheim, performance of Diaspora by Robin Fox (Chamber Made production, 2019) - Photo credit: Pia Johnson. 
It could be argued that the practices discussed in this Forum under the suggested term "sound theater" could just as easily be called music theater. Whether a work is considered sound theater or music theater will of course depend on where you stand in the debate on sonic art as a form different to music. While there is a significant overlap, I also believe that the practice of sonic art revolves around sounding and listening as critical and reflexive activities, ${ }^{1}$ whereas music is concerned with structural elements of harmony, melody and metric rhythm and the calibration of these within established, predominantly historical structures. ${ }^{2}$ Put simply, it is the intention, both in terms of the sounding and listening, that differs between sonic art and music. The works that I am keen to explore here grow out of the culture and practice of sonic art, rather than that of music (or the culture of theater with its emphasis on performative gesture for that matter). If this work may be allowed an alternative categorization, I am proposing sound theater as an overarching notion-and electronic sound theater for works critically engaging technology, which is mainly the focus here.

In 2019, in what now seems like a mythical time of uninterrupted artistic activity and unfettered mobility, I had the good fortune to travel to several festivals, and also experienced a generous (by Sydney standards) selection of touring international artists. This exposed me to a range of works that started me thinking about how electronic sound was manifesting differently in the second and third decade of the twenty-first century. I also had the honor of being commissioned to make my own large-scale performance work that developed in a way unlike any I had made previously. ${ }^{3}$

1 In this I am guided by Brandon LaBelle's proposal that "sound art as a practice harnesses, describes, analyzes, performs, and interrogates the condition of sound and the processes by which it operates." Brandon LaBelle, Background Noise: Perspectives on Sound Art (New York: Continuum, 2006), ix.

2 Of course, there has been a consistent effort, especially since John Cage, to allow the extra-musical into music, however I would argue that discussion and analysis of the historical structures of "music" still dominate music discourse. Rather than being considered a marginal aspect of music, I prefer to consider sonic art as related yet having concerns that extend beyond these structures-philosophical concerns with ontologies and epistemologies, subject-object relations, speculative realisms etc.; and psychological and scientific concerns with perception, cognition, and consciousness. These concerns can be applied to music, but they are not at the forefront of the discourse.

3 Created in collaboration with designer/artisan Thomas Burless, A Continuous Self-Vibrating Region of Intensities (retitled in 2021 as We Are Oscillators) is a performance installation environment featuring eight bespoke kinetic objects that explore the vibrations of the voice through cymatics (the morphogenetic effects of sound waves). Excerpts can be viewed here: https://youtu.be/iDQ6cR9onbU. 
I was struck by how these performances, rooted in experimental electronic sound practices, are becoming more performative via their materials, and their digital-mechanical hybrid methods of activation. These activations provide the "sonoturgical" arcs that drive the theatricality, without additional or imposed performative constructs. The introduction to this Forum will survey some of these intriguing performances providing a context for the following invited contributions that explore a number of projects and practices in more depth.

Ironically, much of my current academic argument is against taxonomic mapping, so the purpose of grouping together the practices discussed here is not so much out of a desire to pin down and define, to corral these artists in a paddock of my own fencing. Rather, it is my intention here to explore a range of practices that engage sonic material performativities in a way that has an intriguing lineage and opens new possibilities for further exploration, particularly as mediating technologies become more mobile and malleable. However, the influence of avant-garde music performances-e.g., Fluxus events, or the music theater of Heiner Goebbels-will not be ignored, rather reconsidered through this focus on sounding, listening, and materials.

Attempting not to impose an externally manufactured category, the essays that comprise this Forum for the most part feature "accounts" in which the artists discuss their own practices. Their intentions and preoccupations, expressed in their own words, create resonances and dissonances that may reinforce or dispute the Forum's themes. This focus on experience and practice enacts my commitment to what I have termed a "tomographic approach," in which the embodied, embedded experience of a sonic art event, expressed through "slices" from the inside, informs and enriches the commentary. ${ }^{4}$ In this I am influenced by the epistemological approach of situated and partial knowledges as proposed by Donna Haraway in which the embodied, sited, and experiential is transparently acknowledged in the discussion, rather than writing from a pretense of unlocatable objectivity. ${ }^{5}$ This knowledge is inevitably incomplete and partial, which should not be seen as a problem rather an opening-an invitation-an opportunity for

4 Gail Priest, "The Now of History: Tomographic and Ficto-Critical Approaches to Writing About Sonic Art" (RE:SOUND 2019, 8th International Conference on Media Art, Science, and Technology, Aalborg, Denmark, 20-23 August, 2019), https://www.doi. org/10.14236/ewic/RESOUND19.9.

5 Donna Haraway, "Situated Knowledges: The Science Question in Feminism and the Privilege of Partial Perspective," Feminist Studies 14, no. 3 (1988): 575-99. 
connection with other specific and partial knowledges. It is in this spirit of offering partial knowledges for connection with others that this Forum also has a distinctly Australian flavor.

\section{Then and Now}

My sound practice began in the early 200os, when, in Sydney at least, what marked the live experimental audio scene was its indifference (often to the point of disdain) towards performativity. Populated by people using small electrical devices, mixing boards, and laptops, any gesture that shifted beyond a flick of a finger seemed quite extreme. I entered this culture after ten years in the contemporary performance scene that had been riding high on postmodern waves of parody and camp, with a preference for physical over textual forms. The fact that there was an audience for the quiet, contemplative, and visually minimal came as a shock and relief to me. It is in this respect that I refer not just to a practice of experimental electronic sonic art but to a culture as well. There were a handful of wildly and willfully performative artists, often in the noise genre growing out of post-punk and industrial scenes (see the description of Lucas Abela's performance below), but still the performative language was predominantly drawn from the gestures of playing and an energetic summoning from the sound rather than an additional aesthetically calculated language.

As the next two decades of the century have come and gone, so too have the participants of this scene. Interestingly, this move towards material performativities appears within the practices of both the handful of remaining mature artists, and the next generation. Caleb Kelly, one of the key curators, event producers, and academic commentators within the early 2000 suggests that this shift is a response to "digital fatigue." He explains that there is:

a longing, from the artists, for a physical connection with the materials of their work. In the 20oos, the prevalence of digital production technologies, especially within the digital studio, led to a schism between artists and their materials, one that has only been further widened through developments in the complexity of digital processes.... Thus, makers have become estranged from the means of their practices. ${ }^{6}$

6 Caleb Kelly, "Materials of Sound: Sound As (More Than) Sound," Journal of Sonic Studies 16 (2018), https://www.researchcatalogue.net/view/456784/456785/o/o. 
Sound and materials - particularly in relation to gallery arts, but also associated live performances-is very clearly the area of expertise of Kelly. He founded the Sound and Materials research group at the University of New South Wales, now known as Sound, Energies and Environments.7 For the purposes of this Forum I will differentiate my interests by focusing specifically on how the "material turn" within sonic art manifests firstly in audio performances-gigs and concerts-and secondly, how some of these presentations are moving decidedly into the theatrical context, challenging what constitutes "performance" in this milieu.

\section{Sonic Actions}

Peter Blamey is a leading Australian artist, active since the 1990s. While the presence of performative materials has become more explicit over the years, it is not so much a change in modus operandi but the result of the development and refinement of conceptual preoccupations and creative motivations. Blamey began his engagement with music in the $1980 \mathrm{~s}$ and 1990 s as a drummer in bands. The shift towards sound happened through a keen interest in guitar and microphone feedback. ${ }^{8}$ Since then Blamey's work has maintained a focus on flows of energies manifested as sound. There is a certain respect and agency given to these energies so that he does not tame them, rather he creates conditions and situations that encourage them into existence and transformation. This is evident in his early 2000 s experiments with mixing-desk feedback, a minimalist process with the potential of maximal sound, in which a mixing desk's various outputs are fed back into its inputs creating its own feedback loop, modulated through adjustments of volumes and frequencies. Developing from this are his explorations in what he calls "open electronics," feedback systems using discarded motherboards. These manifest as both installations as well as a performance series titled Forage. Blamey places clouds of copper wire onto an assortment of scavenged motherboards connected to small battery-powered amplifiers, gently nudging them into different

7 Kelly has edited two issues (16 and 18) on "Materials of Sound" for the Journal of Sound Studies. His most recent curatorial ventures include Materials, Sounds + Black Mountain College (Asheville, NC, June 7-August 31, 2019) and Material Sound touring Australia (2020-23).

8 Peter Blamey, interview with Gail Priest for Sounding the Future, July 24, 2015. 
configurations, the interaction resulting in fields of fascinating hum and buzz. Blamey describes these works:

The title relates both to foraging in streets and laneways for the computer components used, and to the way in which the performances involve a "foraging" for the signals coursing chaotically through this lively but unstable electrical environment. 9

Blamey's work actively engages in reuse and recycling as a critique of capital-driven technological obsolescence. His use of photovoltaic (solar) panels in systems of contingent energy scavenging also attests to his environmental concerns. It is the gestures involved in activating these materials in ways that manifest sound that make Blamey's work uniquely performative. In his Invisible Residue performances, Blamey sonifies (via solar panels) the infrared signal of remote controls from long discarded equipment, performing with the signature sounds that each creates. ${ }^{10}$ Along with the engaging and strangely rhythmic sounds, the all-too-familiar gesture of pointing the remote control creates a curious choreography that encourages critical reflection on this action, and its reinforcement of sedentary leisure, particular to the late twentieth and early twenty-first centuries.

Double Partial Eclipse (2014) involves two small photovoltaic panels that Blamey holds in varying proximities to a lightbulb, the resulting current running to ebows placed on an electric guitar. ${ }^{11}$ Blamey "plays" the guitar by modulating the flow of energy to the ebow via distance and angle. Blamey's measured and sustained gesture creates a mesmerizing performativity, as he seemingly plays the light and air. ${ }^{12}$ In a recent performance configuration, Rare Earth Orbits, he uses spinning rare earth magnets and their closeness to electromagnetic coils to create a basic oscillating voltage, which is then amplified. ${ }^{13}$ To generate the spinning he uses a hand clamp,

9 Blamey, “Forage," artist website, accessed June 7, 2021, https://peterblamey.net/forage/.

10 Blamey, "Invisible Residue," recorded in Sydney, March-May, 2015, track 1 on Invisible Residue, sound recording released May 8, 2020, https://peterblamey.bandcamp.com/track/ invisible-residue.

11 An ebow (or E-bow, "electronic bow") is a small device that can be placed on the strings of a guitar that through a magnetic drive field causes the string to vibrate creating continuous tones, amplified by the instrument's pickup.

12 See Blamey, Double Partial Eclipse, performance for video presented as part of Material Sound at Home (Black Mountain College Museum + Arts Center, curated by Caleb Kelly), uploaded May 21, 2020, https://vimeo.com/421135001.

13 See Blamey, "Rare Earth Orbits - Hand/Clamp," recorded January-March, 2020, track 


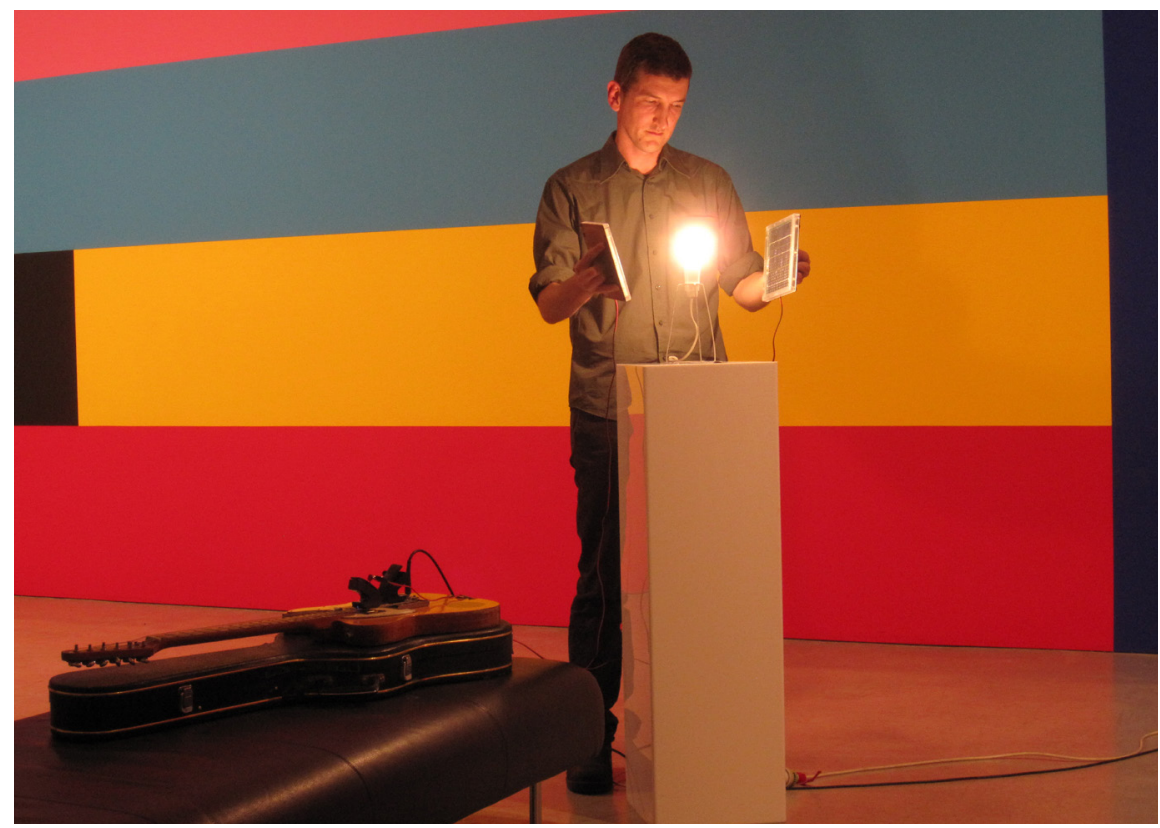

Peter Blamey, Double Partial Eclipse, MCA Art Bar (2014) - Photo credit: Jenn Brewer.

a fishing reel, and a foot-pump activated air vent. The differently scaled actions are focused and minimal in range, with the intensity required to generate what he calls "'handmade' electrical activity” undeniably rigorous and full of intent that renders them highly performative. ${ }^{14}$

However, Blamey's intention is not to invent innovative performance modes but to find ways in which the processes or flows of relations between materials and sounds can become evident to an audience. He tries to create situations in which sonic transductions and amplifications of materials reveal the interactions of their energetic flows. Blamey's focus on obsolete, discarded technology not only engages with the immediate materiality of these objects, but also with "broader ideas relating to electricity, the history of technological artefacts, ecology and experimental practices in the arts." ${ }^{15}$

2 of Rare Earth Orbits, sound recording released May 3, 2020, https://peterblamey.bandcamp. com/track/rare-earth-orbits-hand-clamp.

14 Blamey, "Rare Earth Orbits," artist website, accessed June 7, 2021, https://peterblamey. net/reo/.

15 Blamey, "Selected Motherboard Works (2009-2014)," accessed June 7, 2021, https:// peterblamey.net/selected-motherboard-works/. 


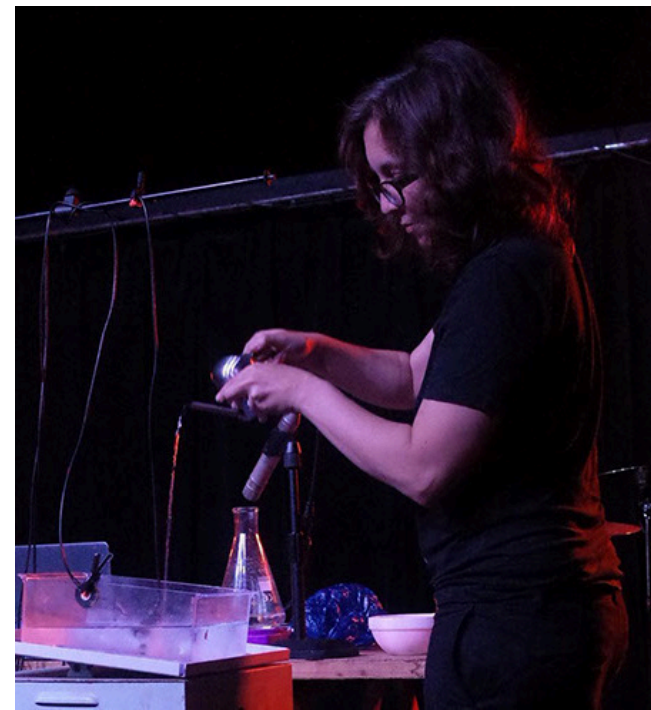

Kate Carr at Les Instants Chavirés (Paris, October 2019) Photo credit: David Lantran.
This affirms Kelly's belief that a focus on materials allows for an expansion out from simply the phenomenal experience of sound to allow for more contextual critique. ${ }^{16}$

As a contrasting example, for the last decade or so Lucas Abela (Australia) has played amplified shards of glass. Pressing his mouth to the glass he blows, slurps, and sings, with changes in the "embrasure," in combination with effects pedals, creating dynamic noise assaults. Inevitably the glass breaks, and Abela is not afraid to slice his face and lips as he continues. ${ }^{17}$ This is undoubtedly a dramatic performance, but one I would argue still comes from an integrated engagement with materials and their sound potentials and the inherent performativity involved in exploring this.

Elements of material performativity are also finding their way into many artists' practices who were previously more laptop-based. Australian artist now based in the UK, Kate Carr's foundational work is in field recording and minimal sampled instruments. Recently she has been integrating "a scientific rocker, a spinning beaker, wind up birds and suspended tape loops." ${ }^{18}$ Working through these material processes, she says, offers a "transparent liveness" explaining that "the risk of failure and malfunction they incorporate and the capacity to physically improvise with things 'at hand"” offer her a spontaneity that she found lacking when only using a laptop and controller. The integration of these live elements is not new and remarkable in itself-this is what instruments offer-but it is the manner in which the exploration of the sonic potentials within materials are defining the scope

16 Kelly, "Materials of Sound".

17 "Lucas 'Granpa' Abela Live," performance of the artist Lucas Abela (also known as Justice Yeldham) recorded live at cave12, Geneva, February 21, 2016, uploaded on June 4, 2016, https://www.youtube.com/watch?v=2aMBMbEWc6I. Graphic content warning.

18 Kate Carr, email correspondence with the author, June 10, 2021. 
and gesture-and are being allowed their own performativity-that is an interesting development within the experimental audio scene.

I doubt that any of these artists would consider their practices within the conceptual framework of sound theater; however, aspects of their work illustrate the integrated relationship of material and its activation that results in a sounding performativity. It is when this same approach to performative materials is scaled up within theatrical contexts that I believe we approach a mode of sound theater that has different motivations and asks for different listening intentions than music theater, with its origins in notated scores and (often but not always) narrative constructions. Sound theaters, I propose, are developing from the culture and practice of experimental audio in which the performance gestures and modes required to activate the sounding potential of materials, both acoustically and via technological manipulations, are inextricably entwined, providing the structure of the composition and the performance-of the performative composition.

\section{Sonic Theaters}

The seeds of this Forum were planted when I saw Diaspora (2019), created by Robin Fox with co-collaborators Erkki Veltheim and Tamara Saulwick, a "science fiction revelation" based on the first chapter of Greg Egan's book of the same name. ${ }^{19}$ Fox is internationally renowned for his audiovisual work using lasers. These concert pieces are undeniably theatrical, but Diaspora marks a significant framing shift to the constructs of theater, working with an overarching (albeit non-textual) narrative. However, the work maintains the conceptual ethos of electronic noise music, and the performative structure and arc of the work are driven by Fox's synesthetic audiovisuality. In Diaspora, the performative material is voltage itself. An essay featuring interviews with Fox and dramaturg/performance-maker Saulwick, exploring the motivations and making of Diaspora, opens our selection of essays.

Another significant Australian work premiering in 2019 was Speechless, a "wordless, animated notation opera" by Cat Hope. ${ }^{20}$ Hope's artistic preoccupations revolve around bass frequencies, noise, and graphic notation. In

19 Greg Egan, Diaspora (London: Millennium, 1997), 5-36. See "Diaspora," Chamber Made (website), accessed June 14, 2021, https://chambermade.org/works/diaspora/.

20 Cat Hope, "Speechless," artist website, accessed June 14, 2021, https://www.cathope. com/art-work-speechless. 
Speechless she uses the Forgotten Children: National Inquiry into Children in Immigration Detention report from the Australian Human Rights Commission (2014) as the unspoken "libretto." ${ }^{21}$ As well as informing the overall themes and message of the work, Hope used the material elements of the report-colors, infographics, and children's illustrations-as inspiration for the graphic score that is presented in the Decibel ScorePlayer App. ${ }^{22}$ The work is scored for an orchestra comprising only bass instruments, and four female vocalists from vastly different genres ranging from death metal to opera, who perform the textless piece. In the second essay of this Forum, Hope describes the intentions and processes of creating this remarkable work, which she herself describes as an opera but may also be productively discussed through the figure of sound theater. Hope's work, while fitting comfortably within the "new music" classification, also embodies an ethos born of noise, pushing way beyond the sonorities and the notation of most contemporary classical music. The expanded sound world released through the scored translation of the materials of this devastating report actively mobilize the greater cultural, contextual, and political resonances, aligning this project with the critical reflexivities of sonic art.

Although it certainly could be argued that Speak Percussion, under the artistic direction of Eugene Ughetti, come from a contemporary classical music lineage, rendering them well-suited to the term music theater, I would argue that their commitment to explorations of sonority, integration of technology, and adventurous collaborations exemplifies electronic sound theater. Ambitious works such as Transducer (2013), co-composed by Ughetti and Robin Fox, focusing on the materialities of the microphone and speaker ${ }^{23}$ or Polar Force (2018), a collaboration with renowned sound artist/field recordist Philip Samartzis, exploring the sonic potentials of ice, ${ }^{24}$ are examples of the kind of material performativities that create sound theater. Also notable are the solo works of Matthias Schack-Arnott (a for-

21 Australian Human Rights Commission [AHRC], The Forgotten Children: National Inquiry into Children in Immigration Detention 2014, https://humanrights.gov.au/our-work/ asylum-seekers-and-refugees/publications/forgotten-children-national-inquiry-children.

22 A network-synchronized scrolling score player created by Decibel New Music Ensemble available as an iPad app, https://decibelnewmusic.com/decibel-scoreplayer/. See the section "Animated Graphic Scoring" in Cat Hope's article further ahead for more discussion and examples.

23 Speak Percussion, Transducer, video performance presented by Arts Centre, Melbourne, Sydney Myer Music Bowl, August 1-2, 2014, https://vimeo.com/184948815.

24 Speak Percussion, Polar Force, video teaser (excerpts) for the world premiere season at the Arts Centre, Melbourne, November 24-December 1, 2018, https://vimeo.com/318170673. 


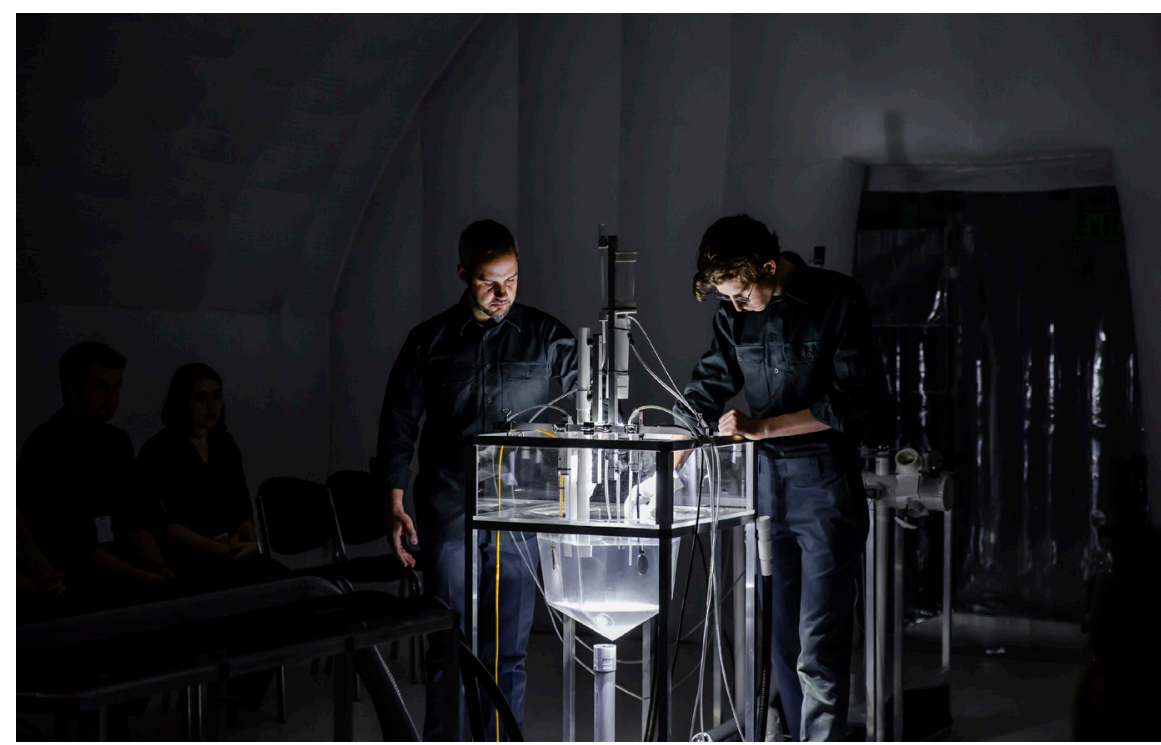

Eugene Ughetti and Matthias Schack-Arnott during a performance of Polar Force (Speak Percussion, 2018) - Photo credit: Bryony Jackson.

mer artistic associate of Speak Percussion), such as Anicca (2016) and Everywhen (2019), that are based on the interaction of the performer and complex kinetic mechanisms. ${ }^{25}$ This results in hybrid, embodied event structures in which the action, materials, and soundings are fully integrated.

While I have been concentrating on Australian works, this tendency to explore sound theaters is evident internationally, particularly at Sonica, a biennial festival presented by Cryptic in Glasgow (UK). A highlight of the 2019 edition was SpaceTime Helix (2012) by Italian artist Michela Pelusio. ${ }^{26}$ Pelusio's "optoacoustic instrument" is a single cable, attached at floor and ceiling, activated to create a spinning standing wave, which with the help of strobe lighting creates a dynamically changing helix. The acoustic sounds of the mechanism, and its electromagnetic signals, are processed to create the tensile escalating soundscape drawn directly from

25 Matthias Schack-Arnott, Anicca, video excerpts from the premiere season, Arts House "Season 2," 2016, https://vimeo.com/208074483; and Everywhen, video trailer with footage from the premiere season, Melbourne International Arts Festival, 2019, https://youtu.be/ kL8ucoPfsLc.

26 Michela Pelusio, SpaceTime Helix, video excerpts, uploaded June 16, 2015, https:// vimeo.com/130903990; and "Working on SpaceTime Helix 2012," work-in-progress footage, uploaded November 24, 2014, https://vimeo.com/112728517. 
this awe-inspiring demonstration of split, bent, and blended light. Another highlight, offering a completely different aesthetic, was Argentinian artist Nicolás Varchausky's Mesa de Dinero/Money Desk (2018). ${ }^{27}$ Using modified money counters and scanners, he amplifies the actions of counting his artist fee. Working with both the aesthetics of the sound of the machines and the functional clarity of the task-based actions, Varchausky sonifies the materiality of money, and the immateriality of the global currency markets in a way that allows the materials to "become" both performers and activists, again exemplifying Kelly's notion of the political potential of material sound.

Kathy Hinde is a Cryptic Artist, presenting many major works within multiple Sonica festivals. In 2015 I experienced Tipping Point (2014), a breathtaking installation that can also be played live, a hybrid format that allows materials to express themselves independently and become performative instruments. ${ }^{28}$ In the third essay Hinde talks with Matthew Sergeant about her works Piano Migrations (2010), Tipping Point and Twittering Machines (2019), that exemplify the way in which she approaches the manipulation of materials so as to engage with their non-anthropogenic contingencies. In this Hinde critically connects our material discussions with current theories of object-oriented ontologies and agential realism.

\section{Theatrical Soundings}

Branch Nebula (led by co-artistic directors Lee Wilson and Mirabelle Wouters, with visual artist Mickie Quick and sound designer Phil Downing as frequent collaborators) presents physical theater works that openly exploit the material performativity of sound. In Wilson's virtuosic solo performance piece High Performance Packing Tape (2018), real-time audio processing sonically elevates the humble materials of office stationery misused as circus apparatus. ${ }^{29}$ In Crush (2020), the sonic integration intensifies with

27 Nicolás Varchausky, Mesa de Dinero [Money Desk], video excerpts from the performance at the collective exhibition "El Centro en Movimiento 2. Máquinas e imaginarios" curated by Rodrigo Alonso, Terraza de la Sala Sinfónica, CCK Centro Cultural Kirchner, Buenos Aires, February 24-25, 2018, https://vimeo.com/325933410.

28 Kathy Hinde, Tipping Point, video excerpts from the installation at the $10^{\text {th }}$ Sound Festival (Aberdeen, UK), Wooden Barn, Banchory, November 2-8, 2014, https://vimeo. com/113274669.

29 Branch Nebula, High Performance Packing Tape, video trailer, uploaded December 18, 
several sections driven by audio activations. An enormous sculptural lattice of PVC piping turns into a ructious aeolian organ with the assistance of an industrial vacuum cleaner. A searing dronescape is created when the performers attempt to drag heavy guitar amps by amplified wires, the physical and sonic tension responding in direct relation. Branch Nebula allows the theatrically sonic to be an integral structural and dramaturgical element of their work, thus rendering their practice truly interdisciplinary.

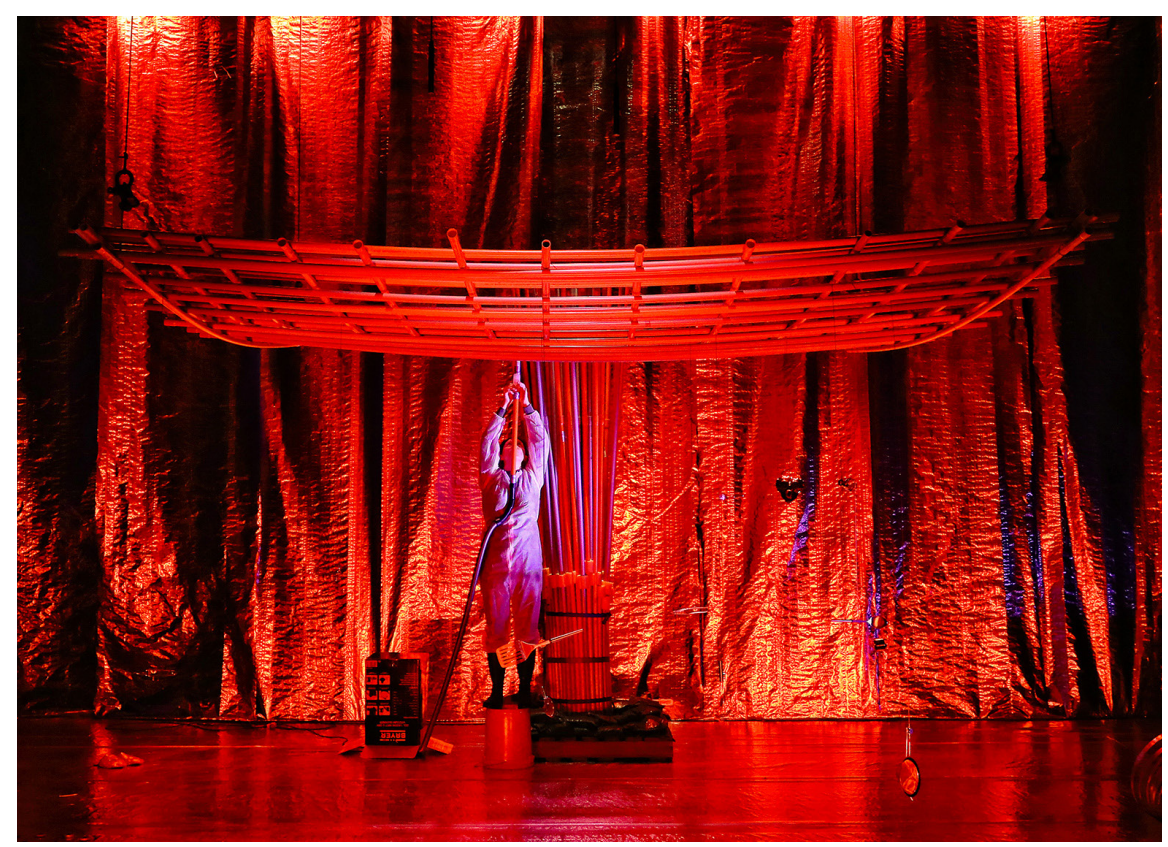

Mirabelle Wouters during a performance of Crush (Branch Nebula, Sydney Opera House, 2020) Photo credit: Prudence Upton.

It is in this context of theater-one which pays exceptional attention to the integration of sound's own theatricality-that this Forum features an essay by composer/sound designer Scott Gibbons, a regular collaborator of Italian theater director Romeo Castellucci and his company Societas. He shares his process notes and musings on developing the sound world for the company's recent project, BUSTER. We are privileged to learn of Gibbons's material experimentations and manipulations as well as some new strategies required for collaborating remotely in global pandemic conditions.

2019, https://vimeo.com/380389913. 


\section{Sonic Thingness}

I can date the initiating spark behind this Forum further back to 1998, when I had the pleasure of seeing Heiner Goebbels's Black on White (originally created in 1996 as Schwarz auf Weiss) at the Adelaide Festival. I recall the moment when a musician from the Ensemble Modern put on a kettle to make a cup of tea. As they waited, they ignited a tea bag, its flaming convection sending it aloft. This magical flight was accompanied by the kettle's whistle; Goebbels says this is "a C major triad, which first the flute player and finally the whole orchestra play along with." ${ }^{30}$ By inserting this simple domestic action (among many others) into the orchestral context, Goebbels intended "to create an un-hierarchical balance in the world of sounds." ${ }^{31}$ However, in the process of introducing the sounding functions of objects, he realized that they, in fact, began to exert power over the musicians. Discussing the presence of these material situations in his early works, he says:

the presence of things might not yet act as a major character of the works in total, but the things rather show up, they capture the space, they conquer more and more the performances and the compositions, they choreograph the words, the movements and actions. The more they insist on their being, the more they call for respect, for their own timing. ${ }^{32}$

In Stifters Dinge (2007) Goebbels finally allows the objects full reign with the piece featuring no (visible) human agents, only five pianos, mechanical devices, as well as recreated elements such as rain, fog, and ice. Goebbels describes the effect of the integration of sounding "things" on an audience:

It demonstrates a different way of experiencing, or even confronting, the way we perceive the sounds of things on a day to day basis. It gives us a bigger freedom for our imagination and also it avoids this enormous reflex we have to upload things with an anthropomorphic center. Those sounds also avoid the reflex to mirror ourselves, to identify ourselves with what we see and hear. Sounds of the things do not allow an easy identification. And that is what I

30 Heiner Goebbels, "The Sounds of Things," in Sonic Thinking: A Media Philosophical Approach, ed. Bernd Herzogenrath (New York: Bloomsbury, 2017), 93.

31 Goebbels, "The Sounds of Things," 92.

32 Goebbels, 93. 
basically try to work on: not to work on a direct encounter with somebody we can recognize, but rather on an indirect encounter with alterity. ${ }^{33}$

In a 2011 lecture Goebbels also references this alterity suggesting that his use of objects and processes has the intention to destabilize the audience's sense of self-identity, offering an "insecure confrontation with a mediated third ... the other." 34 Once again, we see how an engagement with the material soundings as performative events can lead to contemplations of political and philosophical context, beyond the sensorial pleasures of sonority. While Goebbels's reputation as the master of "music theater" may seem to undermine my argument for sound theater as something apart, ${ }^{35}$ I would propose that considering the work of Goebbels through the proposed premise of a sound theater that focuses on material behaviors and their sonic consequences allows for an enhanced appreciation of his practice.

\section{Sonic Flux}

The focus on materials, objects, and their activation as functions and tasks also brings Fluxus events (influenced by avant-garde Cagean practices) into focus. Douglas Kahn describes the shift in the way sound is considered in Fluxus:

The historically earlier question of What sounds? receded in Fluxus and was replaced with questions such as Whether sounds? or Where are sounds in time and space, in relation to the objects and actions that produce them ${ }^{36}$

Kahn highlights the "incidentalness" in the way in which sounds were, or in fact were not generated. In something like George Brecht's' Incidental Music (1961), fulfilling the task takes precedence over generating a sound. ${ }^{37}$ Simi-

33 Goebbels, 96.

34 Heiner Goebbels, "The Aesthetics of Absence," European Graduate School Video Lectures, May 1, 2011, 33:56-34:04, https://www.youtube.com/watch?v=2yRjR4aGXRU.

35 Goebbels's work is in the lineage of Mauricio Kagel's stage pieces such as Staatstheater (1971). While space does not allow further discussion, Kagel will appear briefly in the following essay "Sounding Digital Consciousness."

36 Douglas Kahn, “The Latest: Fluxus and Music [1993]," in Sound, ed. Caleb Kelly (Cambridge, MA: MIT Press, 2011), 33.

37 Kahn, "The Latest: Fluxus and Music," 34. 
larly in Shiomi Mieko's Boundary Music (1963), the artist calls for the action of making "the faintest possible sound to a boundary condition whether the sound is given birth to as a sound or not." ${ }^{8}$ However, ultimately Kahn is critical of how sounds are still musicalized within the Fluxus mode:

From the standpoint of an artistic practice of sound, in which all the material attributes of a sound, including the materiality of its signification, are taken into account, musicalization is a reductive operation, a limited response to the potential of the material..$^{39}$

Here Kahn provides us with the language with which to argue for a sound theater practice. The practices of material sound performance explored above are not simply musicalizing the sonic consequences of material interactions but are attempting to engage more fully with the cultural contexts this material sounding implies and activates.

The engagement in the event of material sounding was not confined purely to American and European explorations, as evidenced by Japanese artist Shiomi's text score cited above. For this Forum, it is through the collaborative work of artist-composer Kosugi Takehisa and performer Kazakura Shō that this era and aspects of performative sound materials will be further explored. Christophe Charles, a Japanese-based artist and academic, had the privilege of working with Kazakura. His detailed historical research includes excerpts from a personal interview with Kosugi and original translations that allow the artists' significant presences to be felt. What is revealed is a fascinating approach that focuses on how these artists-one from music, one from theater-created a collaborative practice through a shared engagement with the materiality of space, time, and the unseen/unheard flows of energies. The influence of artists such as Kosugi and Kazakura can be experienced in the performative material soundings of contemporary Japanese artists, such as ASUNA and his mesmeric durational drone piece 100 Keyboards (2014), ${ }^{40}$ and the sublime sonic kinetic scrapyard of Umeda

38 Shiomi Mieko, quoted in Kahn, 35. Throughout this Forum the Japanese convention of placing the surname first is adopted.

39 Kahn, 31.

40 ASUNA, 100 Keyboards, video excerpts from the live installation of "ASUNA: One Day Exhibition" at the Gallery Kapo, Kanazawa, July 2016, https://www.youtube.com/ watch?v=Vh3H6x1GFn4. See also the full performance at the Full of Noises festival, Barrow-in-Furness, August 17-19, 2018, https://vimeo.com/351364974. 
Tetsuya's Things That Don't Know/Ringo (2017), ${ }^{41}$ which also initiated my thinking around material sound performativities and sound theaters. ${ }^{42}$

\section{Sound-/Music Theaters - Together Apart}

Aspects of avant-garde music, Fluxus, and music theater works (such as those by Heiner Goebbels) all potentially exert a "musical" influence on the projects discussed here. However, I also hope to have revealed how these projects engage a performativity that moves beyond and away from the structures of music to that of material sounding. A key part of this is an emphasis on sonorities that arise from gesture as functional task creating an integrated performance-sound structure. Also pertinent is an intention to create contexts in which listening engages with both the phenomenal sound, but also opens up historical, political, and contextual understandings. I am the first to admit that I have not made a watertight defense. However, what I hope I have done, in both this introduction and the selection of invited essays, is to present a number of connected perspectives, drawn from experience, that allow for a productive consideration of the practice of sound theaters. Inevitably, just as no one has yet managed to clearly extract sonic art from music, sound theater also cannot, nor should be, completely extracted. Rather, the two might be considered through Karen Barad's proposal of a cut or separation that is, within one move, both "together-apart," a proposal, based on quantum field theory, that defies binaries and allows for people, thoughts, situations, and things to contain itself and other as separate continuities. ${ }^{43}$ I leave you to consider the possibility of "sound-/music theaters," existing, both together and apart, with the specificities to be considered contingently, intentionally, and contextually.

Gail Priest

41 Umeda Tetsuya, Things That Don't Know/Ringo, excerpts and interview from the Sapporo International Art Festival 2017, uploaded on December 28, 2017, https://youtu.be/f2zwWXaJAAc.

42 These are artist who toured Australia thanks to the indefatigable efforts of artist-promoter Lawrence English.

43 Karen Barad, "Diffracting Diffraction: Cutting Together-Apart," Parallax 20, no. 3 (2014): 168-87. 


\section{Sounding Digital Consciousness: Robin Fox \& Chamber Made's Diaspora \\ Robin Fox and Tamara Saulwick interviewed by Gail Priest}

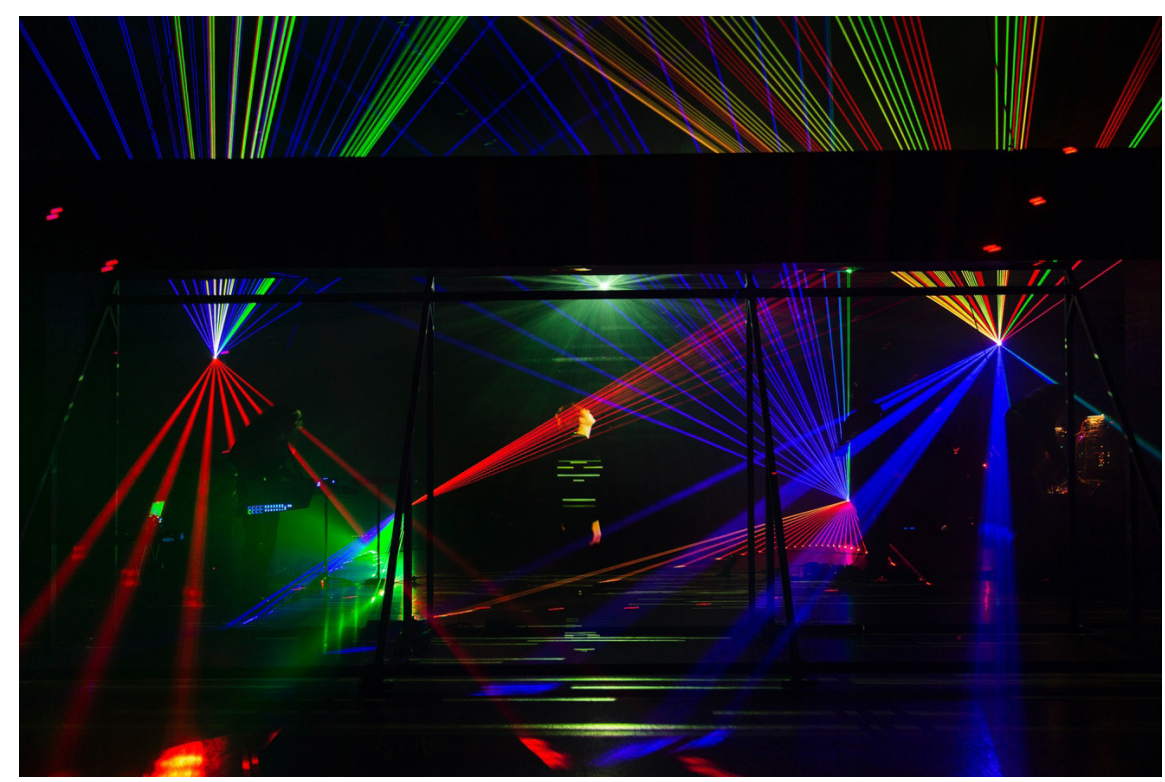

Georgina Darvidis, performance of Diaspora by Robin Fox (Chamber Made production, 2019) - Photo credit: Pia Johnson.

Robin Fox's Diaspora (2019) is a hybrid audiovisual event shaped by a "narrative" of sorts that transforms the live electronic music gig or concert format into that of a theatrical experience in a way that might be described as electronic sound theater. ${ }^{44}$ In the following essay, fragments from interviews conducted with the project's lead creator Robin Fox, and co-director/dramaturg Tamara Saulwick, are presented as input and stimuli, in an attempt to grow and develop this notion, or this consciousness, of electronic sound theater, in a manner that is not dissimilar to the coming to consciousness of the entity that is the protagonist in this impressive work.

44 Diaspora premiered at The Substation as part of the Melbourne Festival, October 3-6, 2019. Concept, creation, composition, electronics, and lasers: Robin Fox; co-composer and violin: Erkki Veltheim; dramaturg and co-direction: Tamara Saulwick; ondes musicales and Moog synth: Madeleine Flynn; vocals and theremin: Georgina Darvidis; video art and system design: Nick Roux; lighting design: Amelia Lever-Davidson; costume design: Shio Otani. 


\section{Origin Stories}

It was while experiencing a performance of Diaspora in 2019 that I began to develop this impression that there is an evolving practice of electronic sound theater that might be productively considered as not entirely the same as music theater. As discussed in the Forum introduction, the theatrical outcome of these works is surprising due to the composer-creators' practices focusing on digital, and frequently non-gestural forms of experimental electronic music and sound art. Fox's background incorporates both composition (he has a $\mathrm{PhD}$ from Monash University) and he has worked as a composer and sound designer for dance; however, considering the nature of his practice, which is intensively electronic, noise-based, and non-figurative, the move to instigating his own complete theater work might seem surprising.

Since the late 1990s, Fox worked extensively on laptop to create live processing systems, including a well-renowned collaboration with Anthony $\mathrm{Pa}$ teras. He made a significant move towards the visual in the early 2000 sia experiments with a cathode-ray oscilloscope, ${ }^{45}$ feeding it sculpted noise and projecting the corresponding patterns via live video. This developed into his experiments with lasers. Using a similar process of translating audio voltage to visualized oscillation (and sometimes vice versa), Fox projects the lasers outwards into a smoke-filled auditorium, carving the space into three-dimensional geometric landscapes of tone and noise, in which both sound and image are manifestations of what Fox describes as shared voltage. These projects have become increasingly ambitious, starting with a basic green laser and then moving to the colorful spectacle of RGB. Fox produces works for both standard concert formats and large-scale site-specific performances, such as Aqua Luma (2021), taking place in the Cataract Gorge in Launceston, Tasmania; or Sun Super Night Sky (2020), a laser installation with streamable soundtrack for the Brisbane city skyline.

While Fox's audiovisual works are presented in electronic music and sound art festivals, he has also worked in theater, particularly as a composer, sound, and lighting designer for contemporary dance works. Very early on in his career he was involved with Chamber Made, then known as Chamber Made Opera.

45 A testing device that graphically displays voltages, allowing for measurement and analysis of waveforms and electromagnetic signal. 
Fox: The first large work that I made when I was still at university, studying composition, was with Chamber Made. It was a bizarre revisioning of the Narcissus and Echo myth that I wrote for four turntables, double basses, and operatic voices... [Mauricio] Kagel's Staatstheater really had a big impact on me when I was a student and so these early pieces of mine were very much of that nature. They were based in sound and rooted in sound, but the intent was operatic and theatrical in a kind of oblique way. ${ }^{46}$

When Fox was approached by violinist-composer Erkki Veltheim (then an Associate Artist at Chamber Made) to create a work, he decided to attempt a science fiction opera based on the first chapter of Greg Egan's novel Diaspora.

Fox: One thing that I'd often joked about with opera is: "Why haven't we ever had a science fiction opera?" ... Once it occurred to me that I wanted to make a science fiction opera, I knew exactly what I wanted it to be-a rendering of the first chapter of Diaspora. ... I just loved the description [it gives] of the birth of a digital consciousness - which I had to go to great pains to distinguish from an artificial intelligence. It has this incredible, quasi-mathematical computer "programmery" but also very DNA-driven description of the birth of this life form ... It is incredibly evocative and incredibly musical, actually. ... [It] suggested all kinds of musicality.

Tamara Saulwick, the co-director, dramaturg, and current artistic director of Chamber Made, makes performance works that are inextricably entwined with sound and sound technologies.

Saulwick: I came into sound surreptitiously. I was working just with recorded voices ... documentary materials or first-hand accounts ... So first of all, they became useful in terms of constructing content; then, I became increasingly interested in the materiality of sound, the quality of those recorded things, and the detritus within the recordings-and that became part of the language of the work.

I was working on some solo material, and I'd become very interested in this intersection between live and pre-recorded-video and audio, actually. I was really interested in this slippage between the mediated and the live body and

46 All quotes by Robin Fox are from his Zoom interview with Gail Priest, April 29, 2021. 
voice. Working between recording and liveness is a really fertile space that continues to fascinate me. ... I've [also] been living with a musician [Peter Knight, currently Artistic Director of the Australian Art Orchestra] for the last twenty years-surrounded by a lot of music, sounds, doing a lot of listening and a lot of talking [about sound]. ${ }^{47}$

Saulwick and Knight have collaborated on several of her solo performance projects, including Pin Drop (2010-14), which uses recorded interviews and foley techniques to explore the role of listening within fear; ${ }^{48}$ and Endings (2015-18), with songwriter Paddy Mann, using mobile record players and reel-to-reel devices to create the sound character of the work. ${ }^{49}$ Given Fox's established audiovisual language, Saulwick saw that her role in Diaspora "was to facilitate the work coming into being ... trying to support Robin, but also the whole group to make [the work] the most 'itself."

It is also interesting to note the origins and progression of the company Chamber Made. It was formed in 1988 by stage director Douglas Horton to create original chamber opera works. Composer David Young became artistic director in 2009, and grew the reputation of the company by creating intriguing, opera-in-miniature works, often in private houses, site-specific locations, and expanding into new media and digital realms. Tim Stitz took over in 2013 and moved the company to a model that drew on creative input from associate artists, of which Saulwick was one. Saulwick moved into the artistic director role in 2018. In 2017, the "Opera" part of the title was retired to reflect the contemporary focus on interdisciplinary works that explore the relationship between performance, sound, and music.

47 All quotes by Tamara Saulwick are from her Zoom interview with Gail Priest, May $13,2021$.

48 A radio adaptation of Pin Drop made by Tamara Saulwick and Peter Knight for ABC Radio National (2013) can be listened to at https://soundcloud.com/tamara-saulwick/ pin-drop-radio-adaptation.

49 A radio adaption of Endings by Tamara Saulwick and Peter Knight, in consultation with Miyuki Jokiranta, made for ABC Radio National (2017) can be listened to at http://www. abc.net.au/radionational/programs/soundproof/endings/8188440. Saulwick's most recent project, SYSTEM_ERROR (premiered on July 7, 2021 at Arts House, Melbourne), is a collaboration with sound artist/dancer Alisdair Macindoe, who has created a bespoke instrument from conductive electrical tape in which the performers' bodies close the circuits to create audio. This, I would suggest, is a perfect candidate for electronic sound theater. 


\section{Composing Consciousness}

The sound, structure, and scenography of Diaspora comes from the audiovisual compositional interpretation of the birth of the digital consciousness as described in Egan's text, but with no narrative-based dialogue. (Several of the pieces involve lyrics but these texts operate as part of the sonic fabric rather than as narration.) Saulwick describes the compositional process:

Saulwick: Erkki and Robin quite literally translated what they saw as this kind of arc of development within the writing. They had musical motifs that had direct correlations to ideas in the text, and it was done in a series of parts. One of the reasons why I think Robin always thought that it would be a good source, is that in many ways the language translates very readily to a compositional format, because [it] talks about building layers and complications of theme.

Fox explains the choice of instruments and palette of the composition:

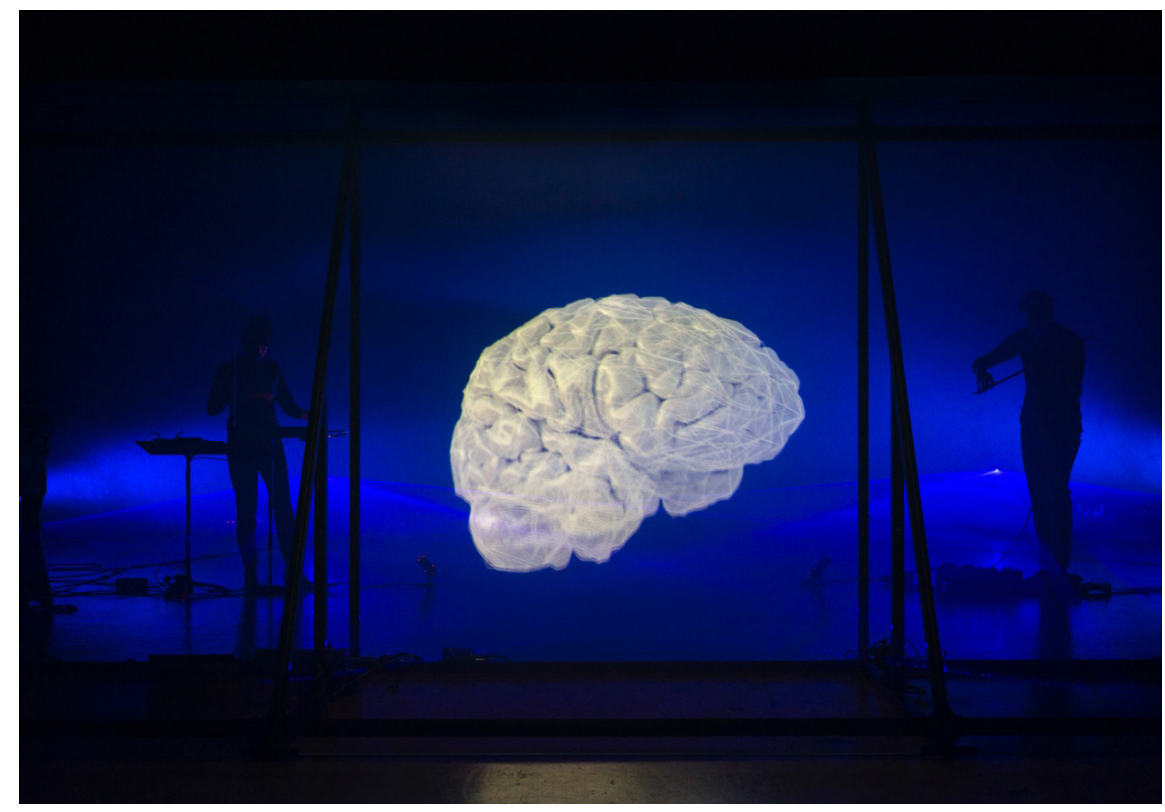

Georgina Darvidis, Erkki Veltheim, performance of Diaspora by Robin Fox (Chamber Made production, 2019) - Photo credit: Pia Johnson. 


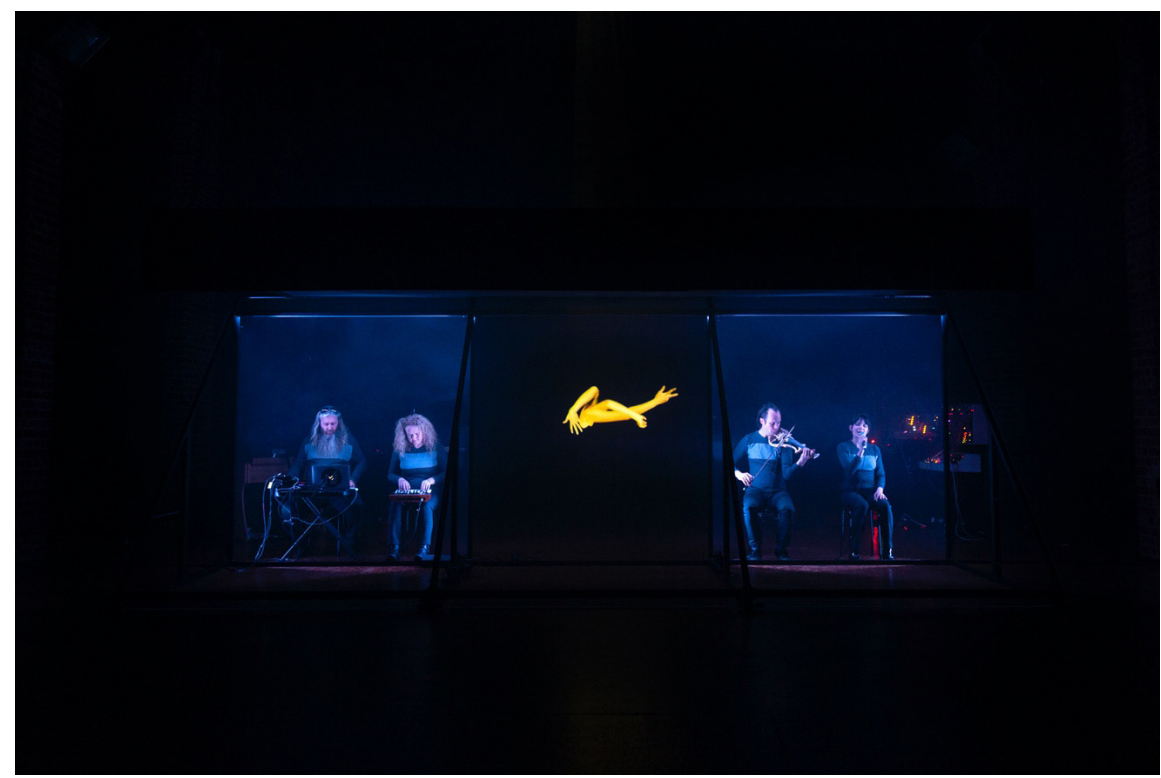

Robin Fox, Madeleine Flynn, Erkki Veltheim, Georgina Darvidis, performance of Diaspora by Robin Fox (Chamber Made production, 2019) - Photo credit: Pia Johnson.

Fox: I'm fixated with modular synthesizers, so I wanted to make [them] a big [feature of the composition]. 5. I also wanted to use the electronic instruments as props so that the machines are part of the ethos of the work. But I also really wanted to work with musicians ... Electronic instruments lend themselves to this kind of automated delivery rather than human gestural delivery. I've always had [an] issue with electronic instruments not vibrating. You don't have the appropriate proprioceptive feedback from a vibrating body. It's really the sound system that's your instrument in that sense. It's not the computer or the software, it's the speaker that's the vibrating thing in the room. Working with Erkki, I was going to be working with violin, so I liked the juxtaposition of that. Working with modular synths [but] then also with the most iconic, conservative, orchestral instrument family. The violin is such an iconic reference point for all kinds of music; it encapsulates that high/low culture that we really exploited in the work as well. ...

50 In 2016, Fox and Byron Scullin co-founded the Melbourne Electronic Sound Studio (MESS) which houses an astounding array of analogue modular synthesizers (many rare), available for members to use (https://mess.foundation). 
I wanted to work with great musicians. Madeleine Flynn is a great musician [pianist] and so the ondes Martenot made really good sense there as an electronic instrument that embodied that theremin like quality. ${ }^{51}$ Then the idea of having a voice [Georgie Darvidis] ... a human voice that would sit alongside the very inhuman construct of a lot of the other aspects of the work. ... It did come from this electronic premise, but there was so much of it that wasn't electronic by design ... I wanted performers to be on stage ... I didn't want to do a sound design that supported the theatrical action or even a sound design that supported a sort of visual installation. Tamara and I would often have these dramaturgical conversations where my position would be: "this is a gig" - a gig in this kind of bizarre set. ...

There were set pieces, but there was a lot of flexibility in the way [Diaspora] was played. I wanted to keep that musicality about the work. I think that's part of my problem with some of these other things that I work on, in contemporary dance, where you have to nail everything down. I deliver the soundtrack in this electronic form, design a sound system and then it's cued the same way every night. It's a show and that's a great way to work, but it's also not very musical. So I did very much have in my mind that idea of this music-driven theater; the music, and the way we composed the music, was really at the core of each section of the work. ...

Even though it did have theatrical or narrative qualities at times, all of the ideas came from the sound and the generation of the sound, and what we were trying to do with the music, not just sonically, but linguistically ... to me music is incredibly linguistic ... [I mean in] that kind of punch card way that notation has of turning [sound] into a sentence structure and a grammatical structure. You have a form so that then, in the same way you would construct a sentence, you construct a phrase, and then you construct a paragraph. I'm always interested in the intersection points between that kind of linguistic approach to music and then sound as another thing which doesn't have that linguistic intent.

51 The ondes Martenot is an early electronic instrument, patented in the same year as the theremin, played with keyboard and a ring that moves along a wire to create ethereal quivering tones. 


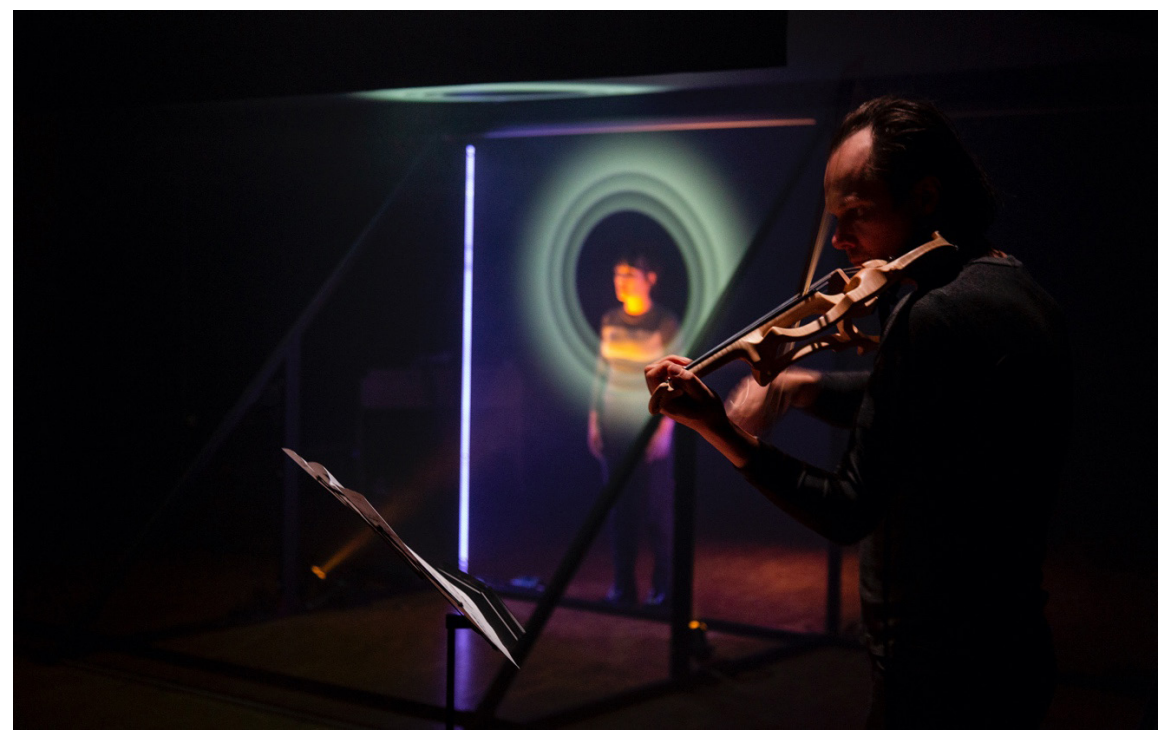

Georgina Darvidis, Erkki Veltheim, performance of Diaspora by Robin Fox (Chamber Made production, 2019) - Photo credit: Pia Johnson.

A key instance within the performance that plays with this musical linguistics is the section that sounds like an interbreeding of a Bach partita and Country and Western hoedown featuring virtuosic performances by Veltheim, Darvidis, and Flynn. For Fox and Veltheim, this piece of very strange composition exemplifies the issue that arises around the cultural context of data that is too easily lost in machine learning:

Fox: The idea behind that was trying to make music that an artificial intelligence (even though we weren't looking at AI particularly) might make. What would an artificial intelligence make if it could make music and why? And because artificial intelligence is algorithm-based, based on data input it seemed logical that it would analyze a Bach violin partita and then analyze a hoedown and realize that structurally they were almost identical, then just put those two things together, because it doesn't have any cultural baggage. It doesn't realize that they actually represent two very different paradigms in terms of music and how we appreciate it as human beings, and in our human cultures. So, I like the idea that in a science fiction world there is no delineation between those ... those forms..$^{52}$

52 Botnik, a studio that specializes in machine-assisted entertainment remixes, fed a neu- 
In another section, Darvidis sings a version of "Somewhere over the Rainbow" that is digitally diced, spliced, and fragmented almost beyond recognition, yet-for a human audience that understands cultural contexts-resonates with the bittersweet longing to be elsewhere and other. These unfamiliar familiarities are even more curious as they emerge from an extended meditative opening sequence (sustained for over twenty minutes) of undulating sine tones and sub frequencies that-along with the accompanying laser light translations carving the smoke-filled airrender the space thick with affective vibration. Fox talks about wanting to play with the balance of these linguistically music and abstract sonic elements:

Fox: It's very difficult to present something that's non-linguistic sonically and have it appreciated without a linguistic lens. I think people still want music and resolution; you know, tonic to dominant resolution-the psychoanalytic safety of all of those structures. ... So, I think with this work there are sections where I just wanted it to sit for a while in places that were very strange and not be concerned about where they were going.

For me, this extended opening illustrates how this performance operates on a sonic art sense of time, one that allows for a more ambient and patient extrapolation, rather than musical and theatrical time that often progresses through the accumulation of actions and established moments. I asked Saulwick how she worked with these different time structures:

Saulwick: I think of [Diaspora] as an expanded concert. The opening sequence was a long sustain. I felt like my job was going "Okay, how can we shape the unfolding of visuals - stage lighting and video materials-to meet that tempo?" In terms of the audience experience, it was very physical, like you were in a big bath of sound ... [with the] massive subs under the seating, the sine tones were kind of actually waving through you physically. I think that places people in time in a different way. They can really settle into it.

ral network a data diet of Country and Western songs resulting in the hilarious classic, "You Can't Take My Door" that can be heard at https://youtu.be/EPs6wdM7 $S_{3} \mathrm{U}$. 


\section{Visualizing Conception}

Perhaps what makes Diaspora seem so remarkable as a performance work is the fact that the composition is, from inception, audiovisual. There is never the sense that the visuals are accompanying the sound-they generate each other, converging to activate the space creating the performativity. As well as Fox's lasers that manifest the full-bodied vibrational sound as three-dimensional wave geometries, exquisite video projections, created by Nick Roux, hang suspended in air, the holographic illusion created by an enormous Pepper's Ghost..$^{53}$ A meteorite emerges out of the depths of the space, making its way towards us. It almost imperceptibly transforms into a brain, an eye, multiple eyes, limbs. Fragmented body parts grow before us, eventually perfectly transposed over the live body of Darvidis, marking the artificial consciousness finding its form.

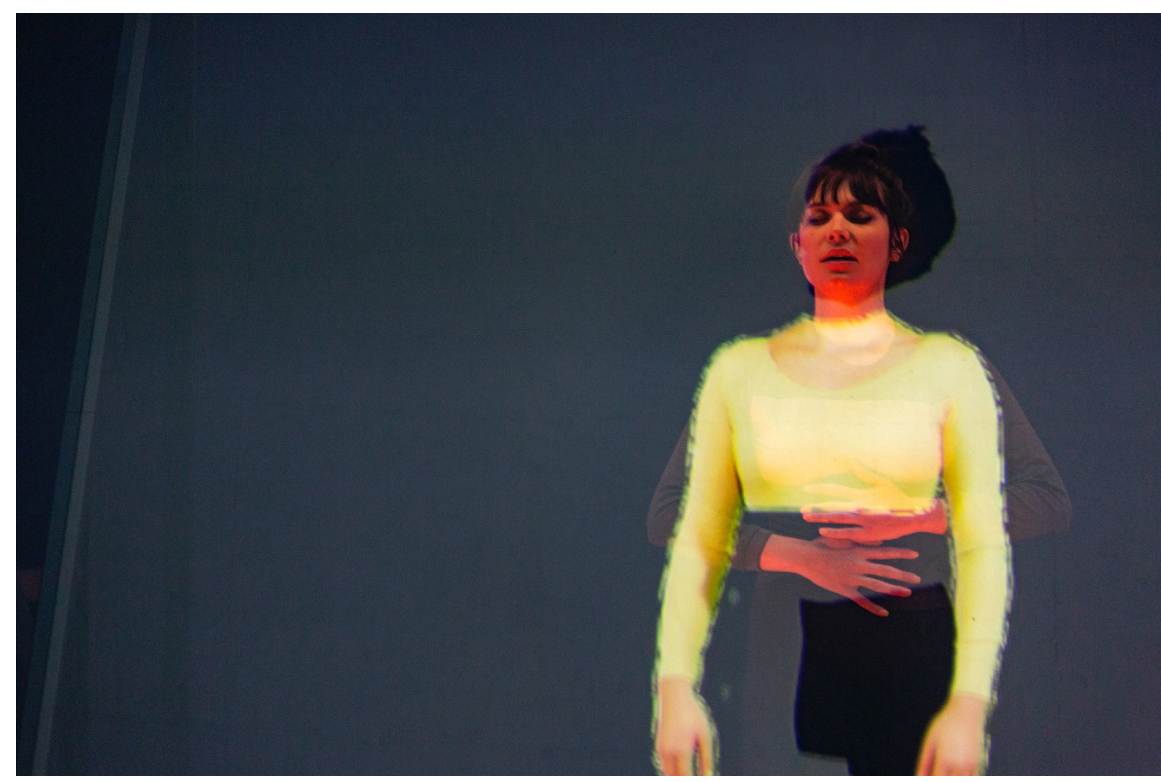

Georgina Darvidis, performance of Diaspora by Robin Fox (Chamber Made production, 2019) - Photo credit: Pia Johnson.

53 A theatrical device whereby a slanted transparent pane (glass or perspex) reflects an image, the source not seen by the audience, so that the reflection seems to hover in space. It is named after John Henry Pepper, the scientist who popularized it in the nineteenth century, although others also claim its invention. 
Saulwick: We had this completely separate development, which was around staging the body in relation to the hologram and what the visual language might start to be. ...With the Pepper's Ghost it becomes a set of pragmatic decisions: how to work with the architecture that the holograph projection surface offers you ... There was some level of dramaturgy [around the body] being behind that structure and then revealing the live body at a certain point; breaking through to the foreground space and then being sucked back into the nether space ... The live body, the digitized body, and the interrelationship between them.

It could be seen as potentially disappointing that the final digital consciousness takes a human form-is this the anthropocentric limit of our imagination? Will we always try to make our technology in our image? However, this is true to Egan's text, in which the artificial consciousness has a choice of avatars but is eventually drawn to a human shape gleaned from its library of images. The work's visual narrative guides us through this process of becoming, making us aware that what is being created is porous, contingent, and includes the potential of so much more.

In the same way that the composition shifts from linguistically musical to sonic, the visual language also shifts between figurative to abstract. The piece concludes with a spectacular explosion of light and sound (referencing the carving of a meteor in Egan's text), in which Fox's stadium concert pieces create the template, celebrating the bursting into sentience of this new consciousness. It's an unabashedly, uncritical, and joyous celebration of a new digital, post-human life. While there may be causes for concern over the consequences of our increased transformation into digital life forms, they are left for others to argue. In Diaspora, the integration of the body within the digital entity attempts a hopeful trajectory that the notion of the corporeal will remain a component of an expanded consciousness. One of the burning issues of digital consciousness construction and substrate mind independence is around how a brain in a vat can sense its environment and replicate the kinesthetic knowledge this generates. In Diaspora, there seems to be the suggestion that corporeality remains significant (even if in some emulated form).

\section{Conclusion: Linguistic Slippage}

Evident in the artists' own words and histories is the slippage between considerations of music and sound. As proposed in the Forum's introduction, it 
is naive to think that sound theater is a completely separate activity to music theater. There is no damage done in thinking Diaspora a work of music theater, framed by music's attendant "linguistic" qualities, as Fox terms it. However, it is also interesting and productive to consider the work's origins in the non-musical, non-linguistic pursuits of sound and audiovisuality, and how this changes the compositional process; how audiovisual affect becomes narrative protagonist, suggesting a different form of performativity; and how this may mark a shift in "consciousness," from music theater to electronic sound theater. 


\section{Opera Activism: Speechless-An Animated Notation Opera for Every Musician \\ Cat Hope}

This article outlines the creative development of the opera Speechless (201719), composed and directed by Cat Hope ${ }^{54}$ At the conclusion of an evolving process of research, composition, workshopping, technical development design, and directorial concepts, the work was premiered at the Perth Festival in February 2019, performed by four solo vocalists, the Australian Bass Orchestra, and a mix of community choirs. The opera is a personal artistic response to global human refugee issues and is based on the 2014 Australian Human Rights Commission report The Forgotten Children. ${ }^{55}$ This article explores the connections between the music, score, and production design of the premiere from the creator's perspective.

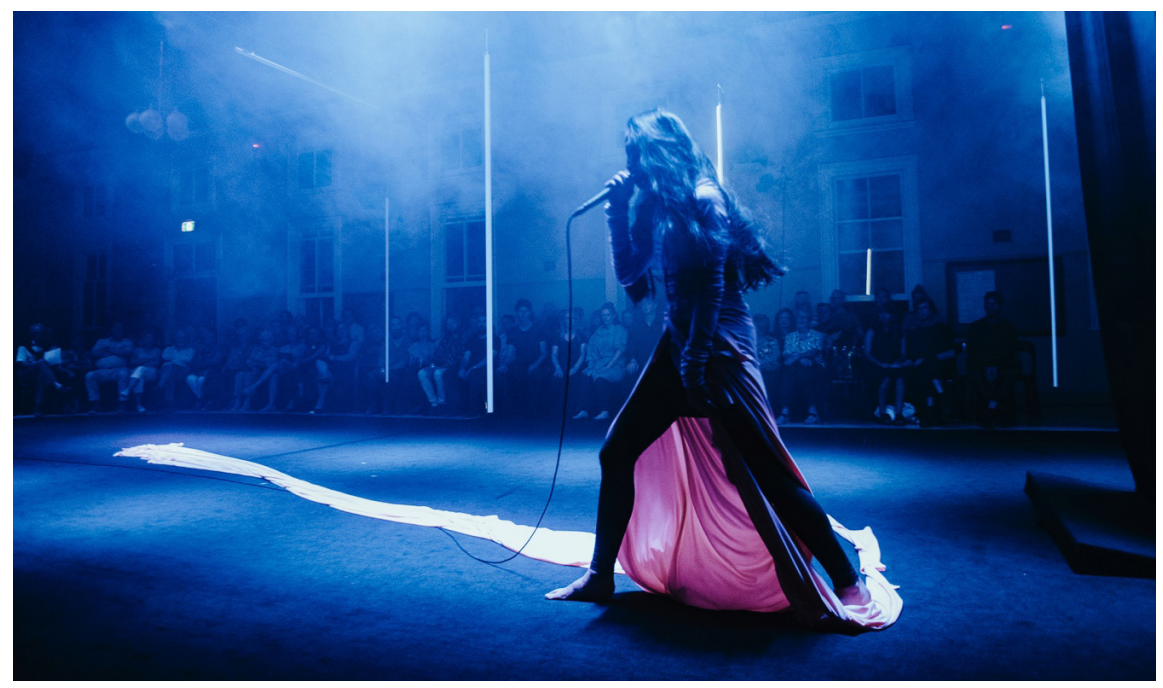

Karina Utomo, performance of Speechless by Cat Hope (Tura New Music production, Perth Festival, 2019) - Photo credit: Rachael Barrett.

54 Short video excerpts with director's commentary are available at https://vimeo. $\mathrm{com} / 345604414$. A podcast featuring excerpts from the opera can be found at https://www. abc.net.au/classic/programs/new-waves/cat-hope-speechless-part-2/12024822.

55 Australian Human Rights Commission [AHRC], The Forgotten Children: National Inquiry into Children in Immigration Detention 2014, https://humanrights.gov.au/our-work/ asylum-seekers-and-refugees/publications/forgotten-children-national-inquiry-children. 


\section{Pluralizing Form}

Speechless is undoubtedly an experimental opera in its sound world and presentation realm, yet it is structured quite conventionally as it pertains to the opera genre-it has an overture, three acts, and an interlude. Each act consists of operatic formulas, such as arias, recitatives, and choruses. A range of traditional compositional techniques (such as theme, variation, development, repetition, retrograde, and inversion of material) are used throughout. Binary and ternary structures appear. The range of intensities of the music create the dramatic sound world you expect from the form.

That is where the links to convention cease. While the opera is sung, no words are used. The opera is designed to be performed by musicians from a wide range of music styles, not just classical or rock artists. The orchestra and choir are built from musicians in the city where it is performed and is composed, using color graphic notation that facilitates this polystylistic involvement. The four soloists are also required to be from different musical styles; and in the case of the premiere, there was a death metal singer, Karina Utomo; an exploratory vocalist, Sage Pbbbt; an opera singer, Judith Dodsworth; and opera/cabaret singer Caitlin Cassidy. The chorus was built from several community choirs and a public call, while the orchestra involved musicians from classical, jazz, rock, and folk styles. The Australian Bass Orchestra, for which the opera is written, is in fact a "mythical company" that only exists as a manifesto outlining a group of musicians who only play pitches below $\mathrm{C}_{4}$. Any musician can participate-as long as they can play these notes on the lower end of the spectrum-and the Bass Orchestra is named after the country where it comes together. The score captures this focus by specifying groups of low brass, low winds, low strings, piano, harp, electronics, percussion, and electric bass guitars.

\section{Animated Graphic Scoring}

The score uses color graphic notation created digitally to develop image files to be read by performers in motion..$^{56}$ The score images outline all the instrumental parts but can be separated out as a series of layers, with each part highlighted for that group. The score is read as a "screen score," presented to musicians in the Decibel ScorePlayer, an iPad application that

56 The animated score can be viewed here: https://vimeo.com/383439576. 


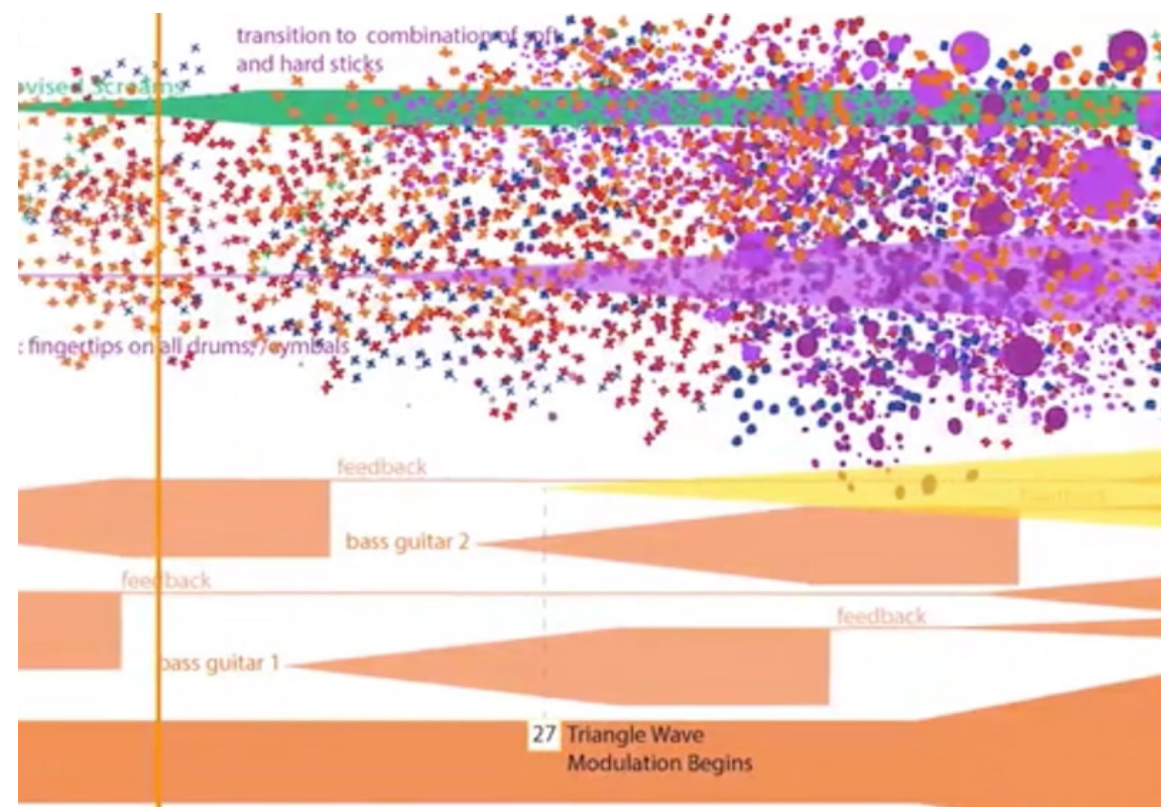

Section of graphic score for Speechless by Cat Hope.

animates the score image, by moving it across a "playhead" indicating the moment of performance. The application is developed by the Decibel new music ensemble, a group of musicians, composers, and programmers based in Australia. The musical director of the Perth premiere, Aaron Wyatt, is the programmer of this application and performing member of the ensemble, and I am the artistic director of and performer in the ensemble. The Decibel ScorePlayer application coordinates the networked reading of predominately graphically notated scores in rehearsal and performance. It features scrolling and "tracking" modes for score reading, as well as a range of other features such as the ability to annotate the score or change the part view without interrupting the progress of the score in motion. Having the music director so involved with the software ensured that any developments or changes to the application could be made during the development phase to accommodate the scale and unique requirements of the work and the processes around it-and this is what happened. During this project, it became clear that the automated score delivery system did not replace the need for a conductor, who provided reinforcement for the orchestra and gestural memory aids for the soloists and choir, who had memorized the score. The app also enabled the incorporation of the production cues for 
stage management, sound, and light. Also, a new way of quickly uploading changes to the score to multiple iPads was developed to facilitate the early workshops where the composer was working with all the musicians. The tablets are connected over a local network, which, when connected to a server, was also used to upload new and corrected versions of the score during the development workshops.

\section{Artistic Activism}

Speechless is my personal response to global human refugee issues, it does not at any time attempt to speak on behalf of refugees themselves. I felt very saddened by, and helpless in the face of, Australia's response to refugees arriving in Australia. This is my attempt to respond to this key issue and encourage others to do the same, making the project a kind of artistic activism. ${ }^{57}$ The report that the opera is based on, The Forgotten Children by the 2014 Australian Human Rights Commission (see supra), is a key document in the public learning about the treatment of refugees in Australia, particularly significant because it was rejected in the Australian parliament as "biased" when presented by the head of the AHRC, Gillian Triggs. As a result, people still languish in detention today, seven years after this report was issued.

The opera is very literally based on this report: the graphs in it are used as sources for musical "themes," the color scheme of the report's layout is used to describe parts for the choir, while the color scheme of the children's drawings featured in the report are used to signal parts in the orchestra. The colors were sampled from the digital document and added to a "palette" used for all color decisions in the score. Further, the drawings and graphs in the report are engaged as core score material, manipulated, and transformed into images readable as music. It is almost a reversal of the libretto: the musicians "read" the report, while the singers do not use words: the libretto is effectively the score. The opera is designed to create and continue an emotional engagement with the Australian refugee issue and the politics surrounding it, for the musicians that participate and the audiences that experience it. It aims to create empathy for and sympathy with the issue, and hopefully spur people on to action to confront these issues. This was facilitated during the premiere

57 See also Stephen Duncombe and Steve Lambert, "Why Artistic Activism?" The Center for Artistic Activism, April 9, 2018, https://c4aa.org/2018/o4/why-artistic-activism. 


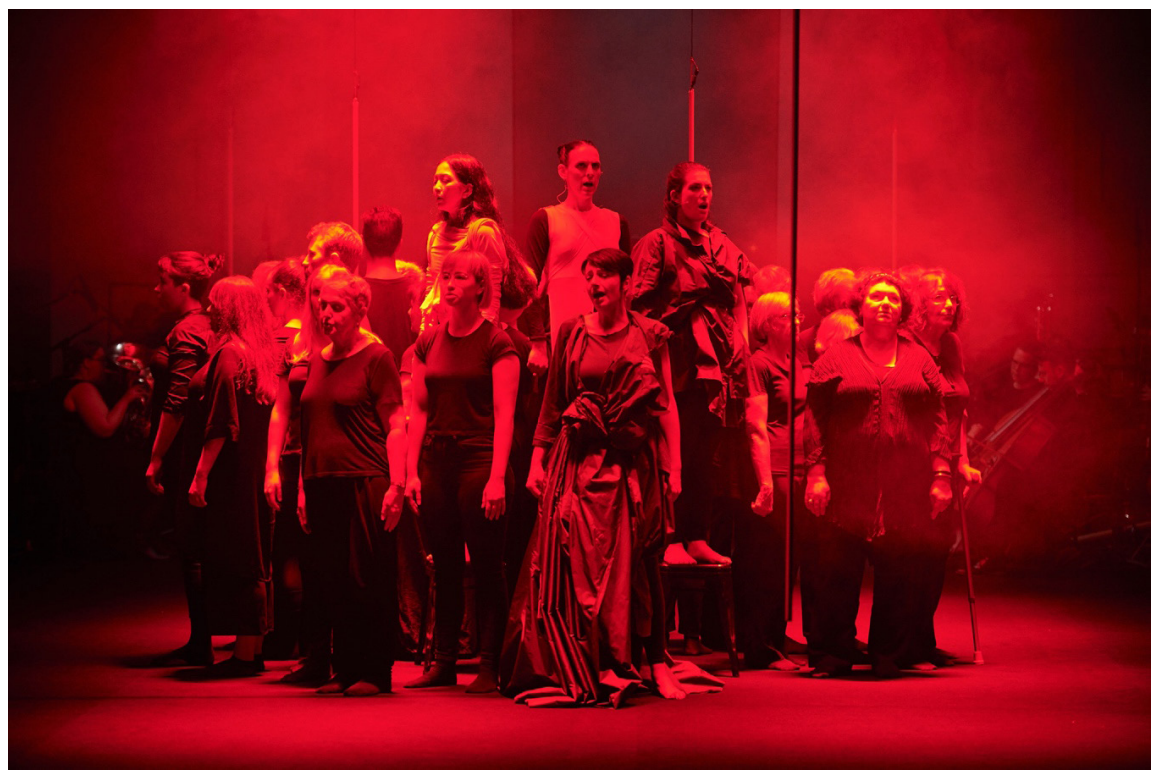

Speechless by Cat Hope (Tura New Music production, Perth Festival, 2019) - Photo credit: Frances Andrijich.

season by providing platforms for refugee advocates before and after shows in talks, stalls, collections, and other opportunities.

\section{Direction and Design}

I directed the premiere, as I had a clear vision where the score, and thus the report, was clearly linked to all production decisions leading to its theatrical representation. I didn't want a narrative for the opera-that would be a story that wasn't mine to tell. Instead, the work consisted of a range of performance art actions, where the brief for the production team was "installation" and "performance art" rather than "theater" and "opera"-an installation approach to scenography. The themes for the design all link to the compositional processes and concept drawn from information in the report: shelter, connection, severance, joining, commonality, belonging/ not belonging, following, isolation, memory, ephemera, long time passing, identity, missing parts, being trapped, and, of course, speechlessness (language and being heard).

I prepared for the direction and blocking of the show by reading film 


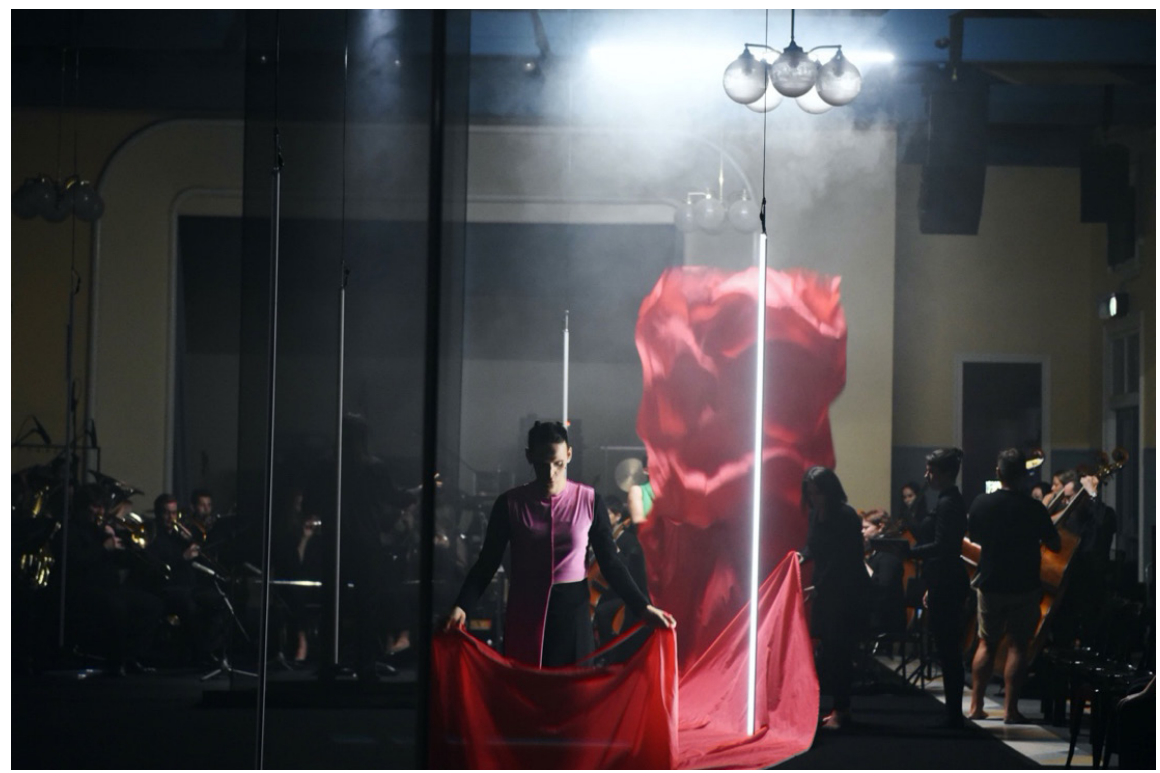

Sage Pbbbt, performance of Speechless by Cat Hope (Tura New Music production, Perth Festival, 2019) - Photo credit: Toni Wilkinson.

theory, Robert Wilson's writing about "silent opera," ${ }^{88}$ and watching Romeo Castellucci's theatrical productions. I particularly enjoyed Werner Herzog's series of books Scenarios, which feature the free-flowing narratives he used as the basis of his films..$^{59} \mathrm{I}$ set about writing my own scenarios for Speechless, which I remained quite faithful to in the end production. I plotted the action against the score, letting the music drive the decision-making process at every step of the way, and providing time frames for various settings. The way that my linear approach to graphic notation unfolds through time was very useful for plotting stage "action" through time as well. The music remained the driver for every aspect of the production design, and this helped me avoid didacticism as much as possible, retaining the abstract qualities I appreciate so much in music itself.

I chose to work with Alex McQuire, a young fashion graduate, on designing the set and costume as one, where performers interact with their

58 Robert Wilson, “Robert Wilson's Theatrical Universe," Limelight, February 6, 2013, https://www.limelightmagazine.com.au/features/robert-wilsons-theatrical-universe/.

59 Werner Herzog, Scenarios, trans. Martje Herzog and Alan Greenberg (Minneapolis: University of Minnesota Press, 2017). 


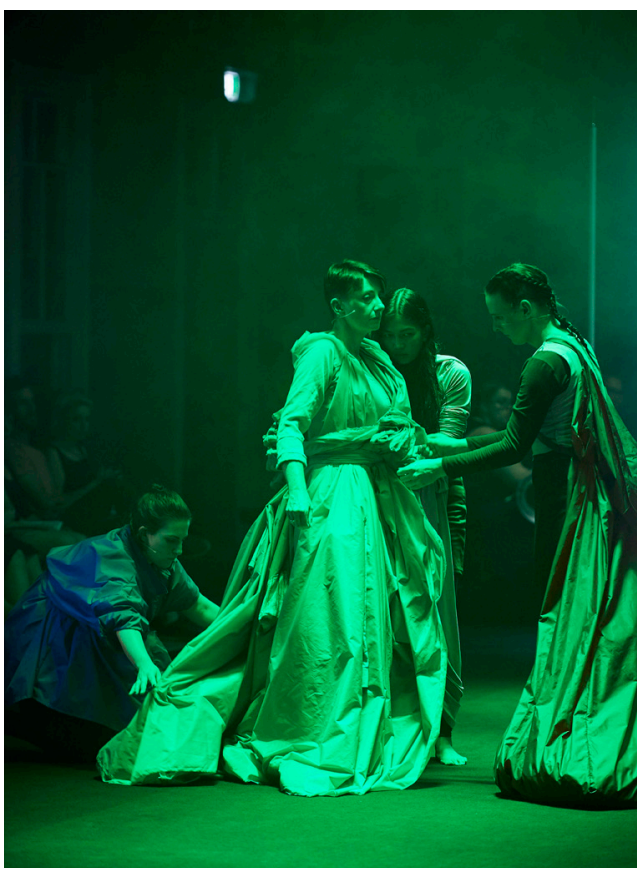

Judith Dodsworth, performance of Speechless by Cat Hope (Tura New Music production, Perth Festival, 2019) - Photo credit: Frances Andrijich. surrounds as extensions of their costumes, and vice versa. The stage design featured long reams of fabric hanging from above that the performers would engage with and transform into various objects as the work progressed. Performers would turn these large fabric pieces into costumes of various scales, backpacks, and pillows. These large fabric reams were intended as surreal surrogate flags-symbolic links to nationhood. Their scale and lack of symbols made them a kind of fictional, nondescript flag, but they still held the intention to describe a belonging of the past and of a potential future. The colors of these flags were selected from

the children's drawings in the report, according to the same color scheme used for the orchestral parts, as a way to link the set to the score and, thus, the music to the set. Each vocal soloist is ascribed a flag color, but that was not necessarily the color of their part in the score, further complicating this notation of "belonging." The flags were over fifteen meters long, and their bright, solid block colors cascaded down from the roof space onto a black carpeted stage-the carpet being the type found in government offices. Also inspired by the waiting rooms in government offices were the audience seats. These were placed "in the round," on the edge of the carpet that defined the stage area, with the orchestra at one end. The choristers were placed among the audience, dressed simply.

I ascribed directorial approaches for each flag color: formality (blue), surreal occurrences (red), dramatic tendencies (green), and emotional responses (pink). Three of the four flags were made of tent fabric, which made its own sound when handled, resembling some of the extended vocal sounds made by the soloists. The pink fabric was the exception. 
It was a sensuous jersey type; soft, stretchy, pliable, and silent. During the performance, the blue, red, and pink fabrics were pulled down from their flag-like hanging position, each in different ways, at a different pace, and for a different purpose. The red was fashioned by the soloists into an extended, oversized backpack the length of one performer, who trailed it around behind them for most of the show. The blue length was folded by the soloist ensemble using formal flag folding techniques, accompanied by a recitative, and attached to that performer in a way resembling a Japanese $o b i$, as an extension of her existing costume from the same fabric. The pink flag was dramatically and quickly whipped away at the beginning of a loud, screeching solo, then gathered up into a kind of portable, cushioning backpack. The green flag was different from the others, in that it had the arms of used clothes sewn into it, referencing the 2001 "Children Overboard affair"-a political controversy where Australian government ministers falsely accused seafaring asylum seekers of throwing children into the sea to secure passage. This flag was stored under the conductor's podium until the soloists ritualistically drew it out, collectively fashioning it into a spectacular and elaborate gown, beautifully designed by assistant director Rakini Devi for the only opera singer. This aimed to highlight the extra attention given to the opera art form at the expense of others, whilst linking to the theme of the work. These different engagements with the flags were the focus for the majority of action that took place on stage throughout.

The space was hung with vertical LED lights, referencing the bars found in many of the children's drawings from the report, in association with other top-down lighting that was plotted to unfold as very slowly moving washes that transitioned across the space, bathing it in red, to moments where the light responds to the music and soloists voices (designed by Matthew Adey with Andre Vanderwert). The choir, divided into four musical parts, each aligned with one of the soloists, interacts largely with the soloists both musically and in terms of action. The choir moves as a whole at certain points, en masse, referencing what was known as Donald Trump's caravan "invasion," a group of over four thousand migrants travelling across Mexico toward the United States in 2018. At one point in the opera, the choir and soloists lie on the floor in the dark, as the room sings with feedback scored for the interlude. They lie with nothing for comfort, only to arise and begin their wander again. 


\section{Affective Frequencies}

The music focuses on very low sound worlds across both high and low volumes. This low sound can create vibrations in the room and listeners themselves, shown to produce more emotional responses. Drones and long, sliding tones are the predominate features that replace melody and tonal harmony, facilitated by my personal notation approach that eschews traditional notation design. The range of pitches (below $\mathrm{C}_{4}$ ) is decided by the players themselves, but my composition prescribes the way these pitches relate to each other. Each group of instruments (e.g., low brass) forms a microtonal cluster, represented by a singular color. The work features improvisational moments for the soloists and various members of the orchestra, inviting them to strike out from the larger group and showcase their unique style. While the audience cannot see the notation, there is a strong connection between color and sound throughout this production, not in any synesthetic sense, but more as a way to connect and express the material from its source. The diverse range of musical styles creates a unique sound imprint that generates a sound world difficult to categorize, and the critical review and audience surveys demonstrated that the work did elicit emotional responses and a heightened motivation to act in empathy with those seeking better lives through asylum.

The audience and media review responses to the premiere season were overwhelmingly positive, with sold out houses over a six-show season. The scoring technique enabled a more open participation for musicians from a wide range of stylistic backgrounds, but also facilitated the unique qualities of the work, such as the focus on long form, drone like sound, extended glissandi, extended techniques, and sections of free improvisation. It enabled the linking of sound, light, and other stage management cues into the musical score and thus the conductor's involvement, resulting in these aligning very precisely with the musical material. It also drove and enabled the high level of abstraction that is at the core of this composition and its production design. 


\section{Further reading}

Crotty, Joel, and Cat Hope. "Speechless: An Operatic Response to Human Rights Abuses in Twenty-First Century Australia." In $O p$ era, Emotion, and the Antipodes Volume II: Applied Perspectives: Compositions and Performances, edited by Jane W. Davidson, Michael Halliwell and Stephanie Rocke, 75-89. London: Routledge, $202 \mathrm{O}$.

Hope, Cat. "The Future Is Graphic: Animated Notation for Contemporary Practice." Organised Sound 25, no. 2 (2020): 187-97.

"Infrasonic music." Leonardo Music Journal 19 (2009): 51-56.

—, and Lindsay Vickery. “The Aesthetics of the Screen-Score." In Proceedings of CreateWorld 2010, edited by Michael Docherty, 4857. Brisbane: Apple University Consortium, 2011. https://www.researchgate.net/profile/ Lindsay-Vickery/publication/301787355_ The_Aesthetics_of_the_Screen-Score/links/ 57283c8608ae586b21e2aod1/The-Aestheticsof-the-Screen-Score.pdf.
—, Aaron Wyatt, and Daniel Thorpe. "Scoring an Animated Notation OperaThe Decibel Score Player and the Role of the Digital Copyist in Speechless." In Proceedings of the Fourth International Conference on Technologies for Music Notation and Representation-TENOR '18, edited by Sandeep Bhagwati and Jean Bresson, 193200. Montreal: Concordia University, 2018. https://www.tenor-conference.org/proceedings/2018/25_Hope_tenor18.pdf.

James, Stuart, and Lindsay Vickery. "Representations of Decay in the Works of Cat Hope." Tempo 73, no. 287 (2019): 18-32.

McAuliffe, Sam, and Cat Hope. "Revealing Sonic Wisdom in the Works of Cat Hope." Organised Sound 25, no. 3 (2020): 327-32.

Milligan, Kate B. "Identity and the Abstract Self in Cat Hope's Speechless." Tempo 73, no. 290 (2019): 13-24. 


\section{Performing Installations: An interview with Kathy Hinde Matthew Sergeant}

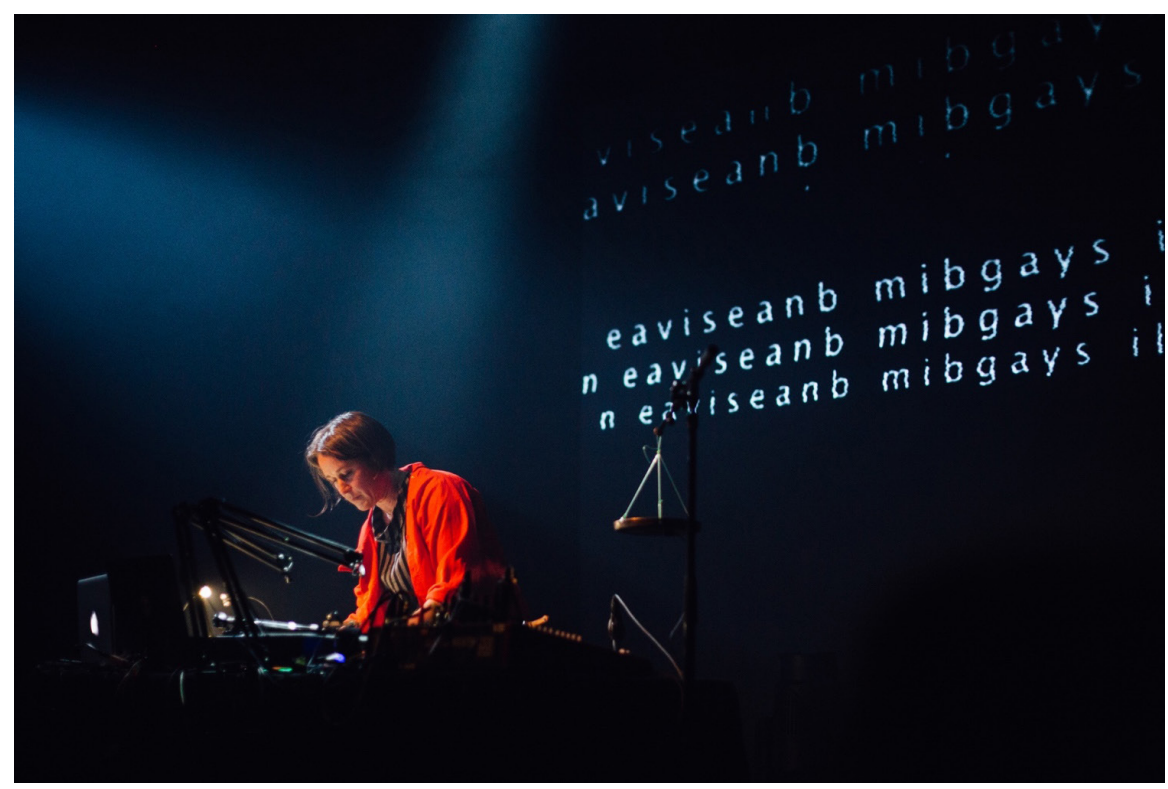

Kathy Hinde, performance of Twittering Machines - Live AV (2019) - Photo credit: Ashutosh Gupta.

Kathy Hinde was the winner of the Sound Art category at the 2020 Ivors Composer Awards, taking the prize for her live work Twittering Machines (2019). ${ }^{60}$ Hinde's output is broad. Her work includes gallery installations, public participatory projects, and sound walks, as well as work that fuses all these elements and more. Twittering Machines - Live AV is her first self-contained performance work, although for many years she has repurposed her more sculptural installation works as instruments with which she performs. It was this interrelation of installation and performance that I wanted to pick at as I met with Kathy (remotely) during the UK's third national lockdown in Spring 2021.

6o Developed at a Cryptic Cove Park Residency and premiered in August 2019 at MUTEK Montréal, followed by the UK premiere in November 2019 at Sonica Glasgow. An excerpt of the work can be viewed at https://vimeo.com/518250341. 
Kathy Hinde: The performance version of Twittering Machines grew from an installation of mine of the same name-along with the necessity to respond to an invitation to perform without being able to "ship" an installation. I had been experimenting with various different "tabletop" sound making set-ups for years, and so this performance grew from these previous experiments-so in this case it did evolve substantially from the original installation work.

Hinde's practice of repurposing her instruments began with Piano Migrations in 2010, which presents videos of birds projected onto the strings of a physical piano. The videos appear to interact with the strings of the instrument through twangs and strums produced by computer-controlled tappers and exciters, seemingly bringing the instrument to life. A later piece, Tipping Point (2014), presents six pairs of connected water jars hung from mechanical arms, controlled by motors to oscillate like seesaws. As the water self-levels across the moving jars, it serves as a mechanism for tuning audio feedback.

Hinde: I first started thinking about my installations as instruments I could perform with live after I'd created Piano Migrations. Despite the main body of the piece being a dismantled piano with all the regular "playing" mechanisms removed, it was only when the work was finished that I realized I could still "play" it [through software]. When I later embarked on the creation of Tipping Point, I then had the premeditated intent to design an installation that could also be the site for live performance. In fact, Tipping Point started a trajectory of work that I feel slips between "sound sculpture" and "invented musical instrument."

There is therefore a clear connecting thread of performativity across Hinde's work. Even when installed, Hinde's works never simply are, they do. When the artist is not performing, Tipping Point sways in a slow dance. And while we are aware of motors whirring under computer control, it also appears as if the water is singing. This dialogue with the performative properties of her materials is something she continually acknowledges in our conversation.

Hinde: Tipping Point looks quite "precise" and "designed", but the way it works is actually quite emergent. The work is all about audio feedback. I don't "make" the sound, but instead set up the conditions from which sound can emerge through resonant frequencies. [In performance] I can shift the glass vessels to change the water levels, but I then have to listen closely to wait and 
find out what my adjustments have changed, and then respond back. It's a balancing act-a dialogue-and in this way it relates to the physicality of sound and how it behaves in space. I can't control it fully and precisely.

From this perspective, I was keen to understand more about Hinde's relationship with her materials. Given that sound always seems to lie within the core of her audiovisual interdisciplinarity, it was perhaps unsurprising that, when the topic of materiality is broached, she is first keen to talk of the materiality of sound itself.

Hinde: One vivid listening experience was on a residency in Bavaria in 2014. I was exchanging "quiet environmental sound recordings" with sound artist Tony Whitehead. Tony sent me a beautiful recording of a leaf, gently, and only slightly, moving in the wind. It was very quiet, yet evocative. I was listening on headphones whilst reading indoors. The window was slightly open and when I listened to the leaf moving in the wind, I became aware of a slight cool breeze on my cheek. I listened to the recording for a second time ... and, yet again, I became aware of the breeze on my cheek. It was somehow spontaneous and intuitive; which got me thinking. Through listening, I seem to have started to have more of a multisensory experienceand engaged in "touch."

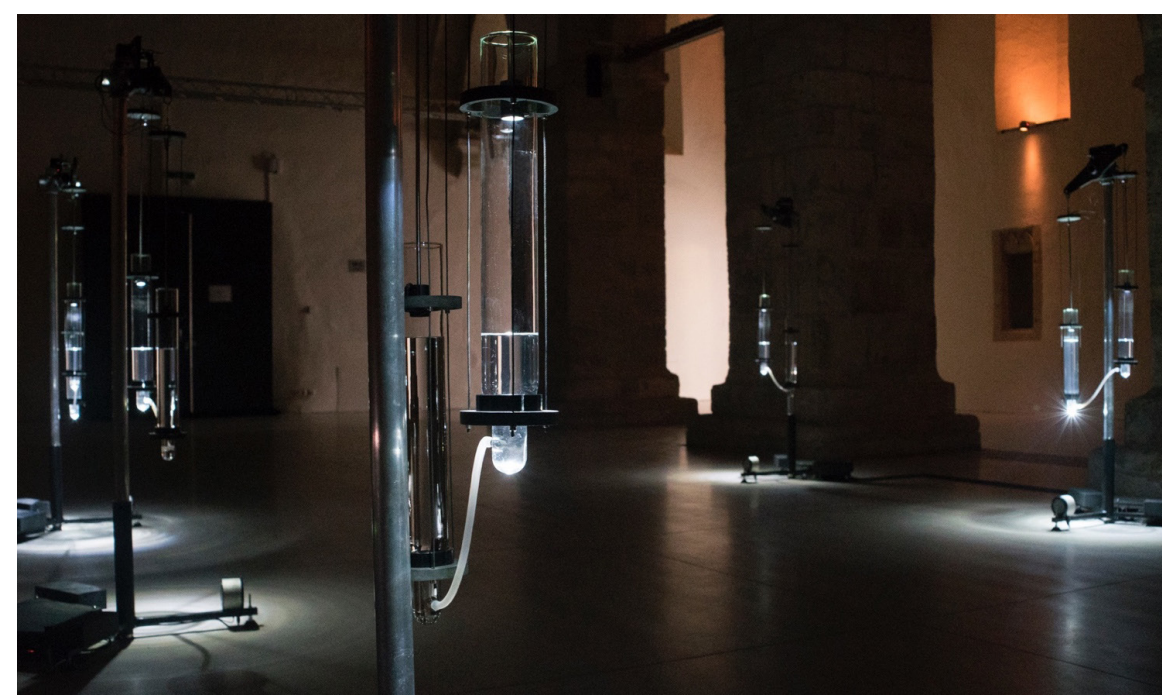

Tipping Point by Kathy Hinde (2014) - Photo credit: Kathy Hinde. 
The sense of tactility with which Hinde describes materials permeates our conversation. When Hinde mentions the materials with which she is working, it is never far abstracted from her sense of physical contact with them.

At this point my mind wanders back to the whirring motors that lie behind the slow liquid dances of Tipping Point. A digital/technological presence permeates much of Hinde's work. Her live performances frequently combine live digital manipulation, analog records, and objects motor-manipulated via a computer. Her installations are often controlled through Max patches. I wondered how this tactility might apply to these domains.

Hinde: I perform live with Piano Migrations, as a duo with Matt [Olden]. I do this by choosing different videos of birds to project onto the piano-and this can produce surprising responses. Through the Max patch, I can control the sensitivity of the translation into physical "twangs" - and I can also control the speed of the movie and the "repeat rate" of the "twang". So, I place the video on the piano and then respond and shape how it responds by listening and observing. So, again, it's something I don't have complete control over-even more so than Tipping Point perhaps.

Hinde has collaborated with Olden for over a decade, beginning with Piano Migrations in 2010.

Hinde: I work on the overall "system" for a piece and what part the Max patch plays within it, but collaborator Matt Olden actually programs the Max patches and I'm not as intimately involved in this. The fact I don't make the Max patches myself probably does make a difference conceptually for me, especially in comparison to my soldered circuit boards and machined, mechanical parts

It's interesting that I don't make my own software in this respect. I suppose it's quite hard for me to consider how a Max patch might have [the same] material qualities as my soldered circuits. I'm quite attached to my laptop. I don't like being without it. But I'd say that Matt Olden's computer is an extension of his mind and body in quite a different way. In that way, the Max patch doesn't present the same kind of discursive materiality for me-but that is different for Matt, he is his machine.

Hinde's description of Olden's laptop as a quasi-prosthesis to his body (in a way hers is not) is beguiling. It seems Hinde identifies the same tactility in Olden's relationship to code as her own relationship with, say, welded 


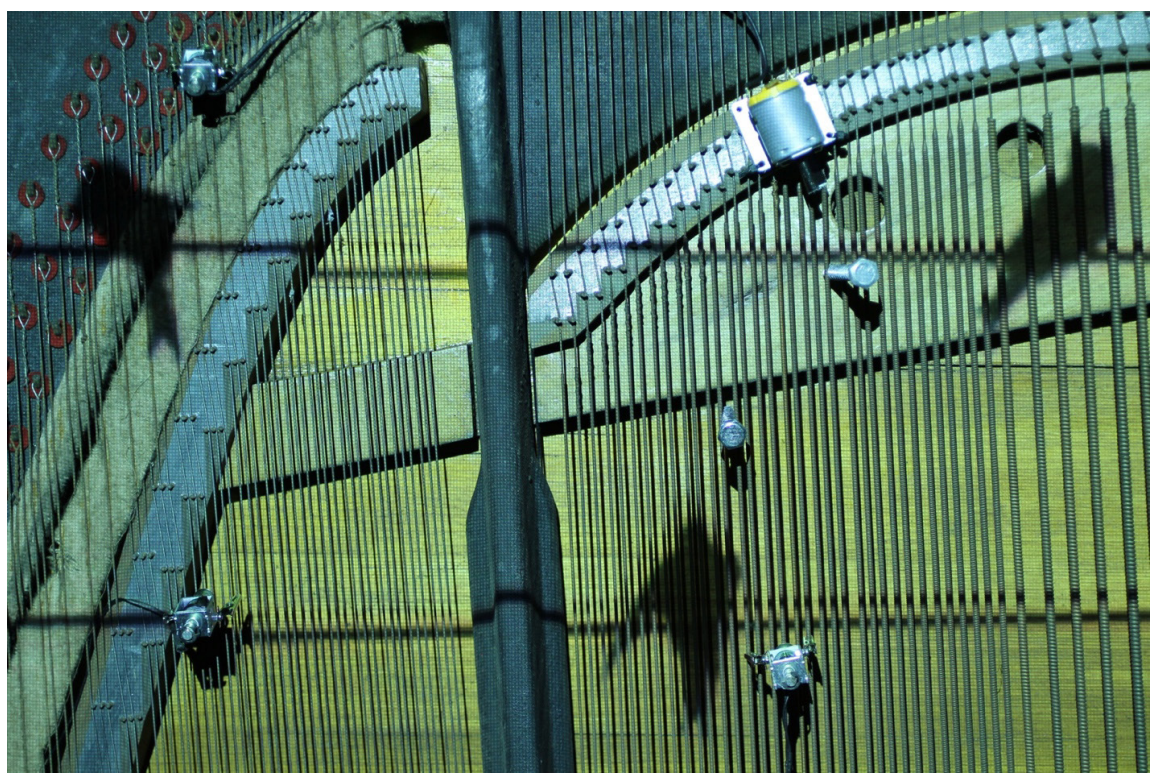

Piano Migrations by Kathy Hinde (2010) - Photo credit: Kathy Hinde.

steel. In this creative partnership tactility still seems to function as a form of common currency.

Such conversation reveals an underlying dialogic quality to the performative aspects of her work in this regard, with words like "listening" and "responding" frequently reappearing. I was interested as to whether she saw her materials as a form of collaborative co-author or co-agent in this regard, to which she responded by discussing her recent audiovisual piece River Traces 1 (2020), her first work with $16 \mathrm{~mm}$ film. ${ }^{61}$

Hinde: I spent a lot of time recording and listening to the river-running my hands in the water, exploring the textures of the plant life, mosses, and rocks through touch. I started to make photogram $16 \mathrm{~mm}$ films with river materials_-(my first photogram film) — and I found it so very tactile. This film-making process felt like a very intimate encounter with both the material qualities of the river and with the process of making an analogue film in this way. What I discovered through these experiments is that film is sensitive. It col-

61 An excerpt of the work can be viewed at https://vimeo.com/446566785. 
laborates. It responds back and improvises. There is a high possibility that what you set out to do will come out "differently."

"So, your materials are a collaborator in this sense?" I asked her outright. Her answer surprised me.

Hinde: Actually, I'm not sure that "collaboration" is the right word in this context. The reason I'm not one hundred percent comfortable with it, is that ... how can the river actively take part? And how can this be an equitable collaboration? I think that the term "collaboration" was a useful conceptual tool when approaching my creative processes with the river. I enjoy thinking about it as a collaboration, which gave rise to subtle shifts in my approach and perception. But my reservations are to do with the fact that the river does not actively give me permission. My premeditated approach-that I intend to consciously leave space for the river to "do its own thing"-gives some agency to the river, but I am not able to sense the "intention" of the river or find a way to hand the same amount of agency that I have over to the river.

I asked her to elaborate further.

Hinde: In working on Piano Migrations, I filmed the birds in situ. It is their movements that play the piano, so maybe I am in some kind of collaboration with them. I'd like to place myself in that situation, but then, I haven't asked them. I'm uncomfortable with saying the birds are (or any other materials/ nonhuman others) authors-not because I want to "claim the credit," but it seems somehow wrong to bring these beautiful creatures into our systems of "ownership" and "authorship." For me, both of these terms lead to notions of "hierarchy" and "capital." This is where I struggle and problematize this idea of assigning nonhuman others as "authors" or "collaborators."

While aspects of Hinde's thought do engage with the kind of active agential materialities so popular amongst artists and critical theorists at the present time, ${ }^{62}$ Hinde's perspective forces us to question the transmissibility of terms in these fluidic domains. Given that birds-or indeed rivers-have no means to express a permission to participate, there are implicit hierarchies of power activated here, a potential "cashing in" of an agency that has not itself been freely granted.

62 For example, Jane Bennett, Graham Harman, Karen Barad, Tim Ingold. 


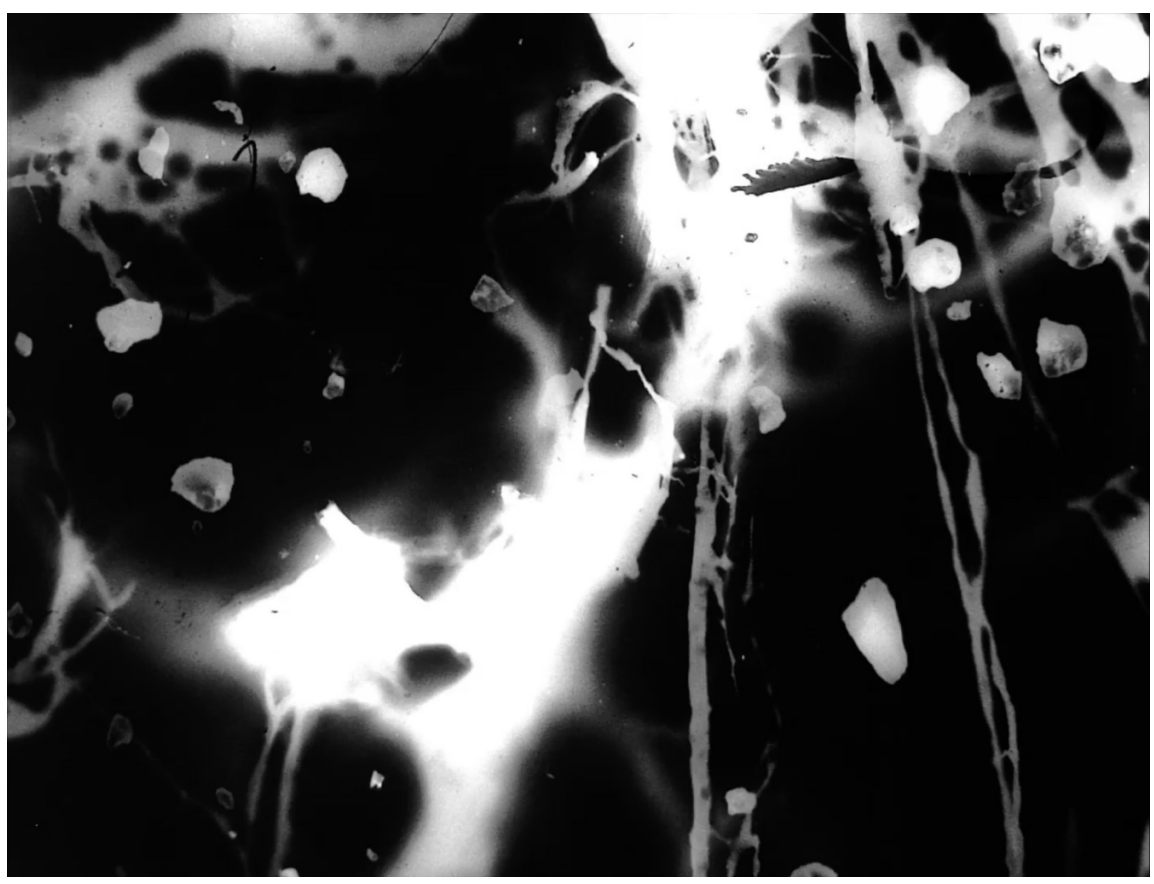

Kathy Hinde, Still from River Traces (1) (2020).

Hinde: I'm aware of some rivers being granted "human status" in order for them to "deserve" more protection from human damage than others, which seems so anthropocentric. Of course I want these rivers to be protected, but the fact that it seems to be necessary to anthropomorphize them in order for this to happen doesn't make any attempt to dismantle hierarchies between humans and non-humans.

Instead of collaboration, then, Hinde-through her work discussed hereis creating non-hierarchical meeting points between herself, the nonhuman world, and her audience. With such thoughts in mind, I was interested in returning to her live work in Twittering Machines - Live AV.

Hinde: My performances within installations are like a cross-fade between installation into live-ness, and back again. It has soft edges. Twittering Machines performance is a departure from this, it is a staged audiovisual performance lasting 30 minutes with a PA and an audience facing the stage. I enter the stage at a specific time to perform... then leave. It's a gig with "hard edges." 
This context puts me in quite a different state of mind, and I do get immensely nervous at the point just before I go on stage, because [the context] feels so different to performing within my own installations. My aim is to reach a state of "immersion" on stage and to find a way I can lose myself in it and become part of it. There is a lot happening "live" in Twittering Machinesenough that I can only just about manage, without it collapsing. Again, there is the situation of not having full control over the whole thing, but initiating processes that create conditions for results to emerge.

Hinde's central operands are still very much present here. There is indeterminacy and performativity, of course, but there is also that sense of touch-a meeting with her materials on equal terms. Through Twittering Machines - Live $A V$ we see an offering of this non-hierarchical perspective outwards to her audience.

Hinde: Ultimately this is why I make work-I want to create experiences for others that somehow embody and share these perspectives, and I would then hope that these subtle shifts in perspective can also be felt-and seep into other aspects of people's lives. It's a quiet and subtle form of activism.

Throughout our conversation, what becomes apparent to me is the extent to which Hinde is perpetually facilitating equal points of meeting and contact between herself, her audience, and her materials. Another form of touch, perhaps. And, maybe most importantly, her work renders visceral the permissibility of such equality within this encounter, all without retort to grand utopian idealism. That, maybe, is the ultimate doing that emerges here. 


\section{Elements of Performativity in the Works of Kosugi Takehisa and Kazakura Shō \\ Christophe Charles}

\section{Presentation}

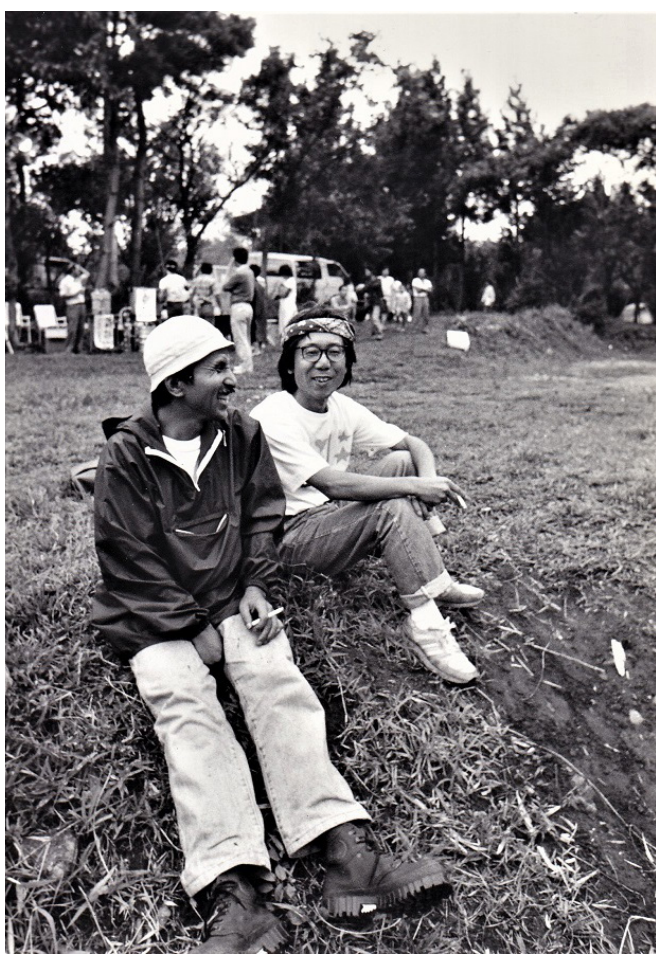

Kosugi Takehisa and Kazakura Shō in front of Kasuga Villa, Tsukahara Pension, Yufuin Town, Ōita Prefecture, "Music Landscape (twelve-hours performance)," August 10-11, 1985. Photographer unknown. Courtesy of Okamoto Takako, The Estate of Takehisa Kosugi / HEAR.
Kosugi Takehisa (1938-2018) was a pioneer of free improvised music and sound art in Japan. He mainly used acoustic and electric violins, voice, homemade acoustic and electronic instruments, and light. He writes in 2014:

The incidental or indeterminate nature of sounds has been one of the major characteristics of my music through improvisational performances and sound installations. In an attempt to transcend conventional musical concepts, I have been introducing electronic territory to my music including both audio frequency waves and non-audio frequency ones such as infrasonic, radio frequency, and light waves. ${ }^{63}$

63 Kosugi Takehisa, "Artist Statement (2014)," Foundation for Contemporary Arts, https://www.foundationforcontemporaryarts.org/recipients/takehisa-kosugi/. 
Kazakura Shō (1936-2007) was a Japanese artist pioneering performance, or happening, as an art medium. Having read works by Luigi Pirandello and Anton Chekhov, he began to do non-theatrical actions in a theatrical context in 1957. Kazakura then became a member of the Neo-Dada Organizers (1960-1963). Nam June Paik wrote that he "embodied the essence of Dadaism." ${ }^{64}$ From that point on he produced objects, paintings, and films, while pursuing his performance work. Kosugi says of Kazakura, "While most artists have since withdrawn from performance, only Kazakura continues to perform. This is very important when considering his art. His constant awareness of 'time' and 'space' makes it possible for him to create various forms of expression." ${ }^{\text {"6s }}$

Kazakura and Kosugi met in 1959. They became friends and continuously collaborated until the passing of Kazakura in 2007. They have close ideas about art and music, space and time, and seem to share a particular interest in how the abandonment of conventional art and music habits are linked to the Dadaist and Buddhist idea of "dismantling the ego."

\section{(Zero) Time}

From the end of the 1950s, the concepts of informel, futeikei (indeterminate form) or fukakutei (indefinite), implying that the form of the artwork continuously changes, were widely explored in visual and plastic arts. Meanwhile, music was mostly conceived as a composition of self-consciously fixed sonic elements. Kosugi and his peers thought that approaching music as "sound" could lead to freeing oneself from conventional musical ideas, and even freeing oneself from one's ego.

From around 1948, John Cage had also been thinking about freeing music composition from the ego. However, Kosugi was already interested in "moving toward a place where the ego could be released freely" before en-

64 Nam June Paik, "Sekai de mottomo mumei na yūmeijin" [The World's Most Obscure Celebrity], in Tokei no furiko, Kazakura Shō [Clock Pendulum, Kazakura Shō] (Kagawa: Sano Garō, 1996), 8-9. Translations are mine unless otherwise noted. See also Akira Suga, "Nichijō no Minaoshi" [Reconsideration of the Everyday), in Neo Dada Japan 1958-1998 - Arata Isoza$k i$ and the Artists of the 'White House' (Ōita City Board of Education, 1998), 150-59. The other members of Neo-Dada Organizers agree that Kazakura was their main source of information about Dada and Surrealism.

65 Kosugi Takehisa, "Chikyū no oto wo kiku" [Listen to the Sound of the Earth], in Kazakura shō ten [Shō Kazakura Exhibition], ed. Kenji Ogami (Ōita: Ōita Art Museum, 2002), 8-10. 
countering Cage's music in $1962 .{ }^{66}$ During his studies at Tokyo University of the Arts, he focused on improvisational music, and began to experiment with "accidental collisions of sounds, as well as the inclusion of everyday sounds." ${ }^{{ }^{67} 7}$ He would perform objets sonores - that is, improvised clusters of (non)simultaneous sounds:

We wanted to produce spontaneous sounds, and our music was influenced by the changes in the movement of our own body or in the environment.... In fact, I was more interested in things that were constantly changing, than in something that was recorded and already finished. ${ }^{68}$

In the process of including everyday sounds, Kosugi and his Group Ongaku (1958-1961) began to use recorded sounds on tape as well. ${ }^{69}$ However, Kosugi was unhappy with the fact that once the sounds are recorded on tape, they are fixed and no longer allow for real-time creativity. $7^{\circ}$

Improvisation implies "automatism, like the action painting of Jackson Pollock ... At the moment of creating a sound the performer gets a very instantaneous approach at the same occurrence/events of sound." The music is "coming from somewhere, not from me, but from outside myself." ${ }^{11}$ From a time perspective, Kosugi further explains that he doesn't need to make choices, because the music just appears as

a very instantaneous event ... This is not like measuring time, in the ordinary time scale, or conscious scale. ... Sometimes time stays there, doesn't continue. This is strange to say, but in my consciousness, when I play, music sometimes stops and I just play spatially or timelessly. The performer does not feel time. The performer can stay at this stage, without time consciousness. ${ }^{72}$

66 Kosugi Takehisa, interview by Christophe Charles, Hear Office, Ōsaka, November 26, 2015.

67 Kosugi, interview.

68 Kosugi, interview.

69 Ongaku can be written using different characters so that it does not only mean music; see Miki Kaneda and Tone Yasunao, "The 'John Cage Shock' Is a Fiction! Interview with Tone Yasunao, 1" Post. Notes on Art in a Global Context, March 8, 2013, https://post.moma.org/thejohn-cage-shock-is-a-fiction-interview-with-tone-yasunao-1.

70 See Kawasaki Kōji, “Takehisa Kosugi no ongaku” [The Music of Kosugi Takehisa], in Ongaku no pikunikku [Music Picnic] (Ashiya City: Ashiya City Museum of Art and History, 2017), 201-14.

71 John Hudak, "Fishing for Sound: An Interview with Takehisa Kosugi (1990)," in Takehisa Kosugi: Interspersions, ed. René Block (Berlin: daadgalerie, 1992), 7-12.

72 Hudak, "Fishing for Sound," 8. 


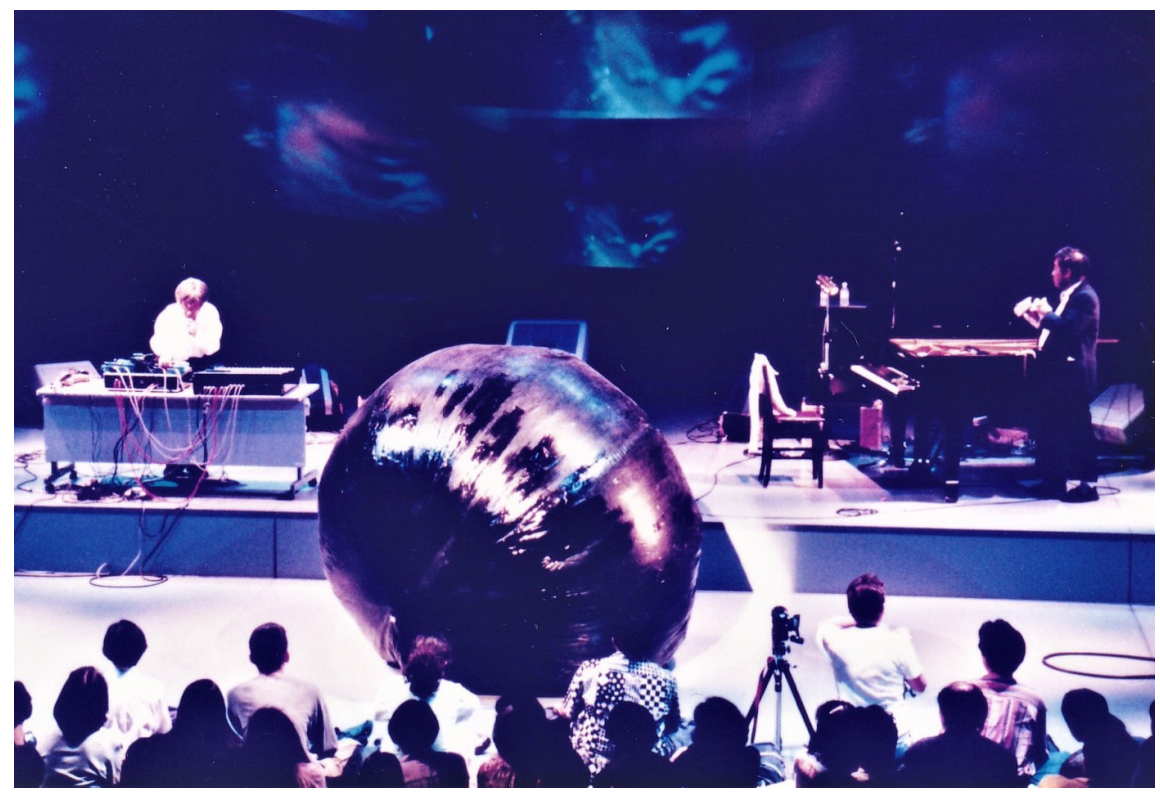

Nam June Paik Fukuoka Prize Performance, Kikyorai [Return Home], NHK Fukuoka Broadcasting Station TV Hall, 30 September, 1995, From right to left: Nam June Paik, Kazakura Shō (in the balloon), Kosugi Takehisa. Photo Ishimatsu Takeo. ( Fukuoka Prize Committee. Courtesy Okamoto Takako, The Estate of Takehisa Kosugi / HEAR.

A close idea has been formulated by Christian Wolff about "zero time": "The zero I take to mean no time at all, that is, no measurable time, that is, any time at all, which the performer takes as he will at each performance." ${ }^{3}$ John Cage would explain it this way: “Zero time' exists when we don't notice the passage of time, when we don't measure it." Talking about o'oo" (1962), Cage added: “I mean when I work on the piece ... or 'in' that piece, I am indeed 'in' zero time. ... I am no longer working towards an envisaged end, in line with the economy." ${ }^{4}$ And Daniel Charles explains:

Silence or absence prevents time from being taken as something already present or already there. Time has to spring. In so far as it springs, it disappears into its own withdrawal. Because of this withdrawal (or "withholding," or "denial") its very granting prevents us from basing our understanding

73 Christian Wolff, "On Form," in Form-Space, Die Reihe 7 (Bryn Mawr: Theodore Presser, 1965), 26-31.

74 John Cage and Daniel Charles, For the Birds (Boston: Marion Boyars, 1981), 209. 
of musical signification on any "constant presence," or any "now-moment" which would require some calculus or measurement concerning a "temporal interval."75

\section{Music as Space Art}

Playing "spatially or timelessly" implies that music is conceived not only as a time art, but also a space art. Kosugi founded the Taj Mahal Travellers group in 1969 and was a member until 1975. Talking about their experiments, Kosugi noticed that there were also conventions concerning the space where music happens, and those conventions needed to be questioned.

A standardized hall may be designed to produce sound properly, but I feel that this standardization also binds the expression in a standardized way.... When the place changes, the experience changes ... I had a concept called "Picnic Band," where you go to a place, make sounds there, and stay in that space. ... It's like enjoying the space there, so I guess you could call it music in that sense, music in space. ${ }^{76}$

This more physical point of view defines Kosugi's central idea of his Catch Wave. When he began to use an electric violin and a wireless transmitter for performances, he noticed that there was radio interference depending on where he was in the space. Every subtle move of the devices would immediately become audible.

This is a way to make people aware of the fact that they cannot hear... This is a kind of "communication of dis-communication" ... Up until now, I've been emphasizing the positive, visible and audible parts, but I want to bring in the opposite, the inaudible and invisible parts. To put it simply, for example, John Cage introduced the concept of "silence." In that case, there is no sound, which means silence. If you think of sound as a positive, it is in a negative dimension, and the positive is utilized in contrast to the negative. In contrast,

75 Daniel Charles, "Music and Antimetaphor," in Musical Signification: Essays in the Semiotic Theory and Analysis of Music, ed. Eero Tarasti (Berlin: De Gruyter Mouton, 1995), 27-42.

76 Yamamoto Atsuo, "Interview with Kosugi Takehisa," in Takehisa Kosugi: World of Sound, New Summer (Ashiya City: Ashiya City Museum of Art and History, 1996), 2-27. 
the positive is utilized, and the negative is implied. If we don't open up our perceptions to that level, I don't think we will be able to create a true inter-media or multi-media form of expression. Nowadays, we talk about computers and multimedia, but that is actually the key point. If we don't make use of the information that we can't hear and can't see, if we don't make use of that information, I think the balance will collapse. I think there is a very basic balance between yin and yang. When you're doing electronic music, the waveform goes back and forth between positive and negative. We receive the positive part, but there is also the negative support. I think that's the key to dealing with things as art.77

\section{Simplicity and Multiplicity}

Kazakura was born in Ōita (Kyushu) and came to study at Musashino Art University (Tokyo) from 1956 to 1958 . Kosugi first met Kazakura at the Yomiuri Independent Exhibition in 1959. Kosugi remembers that many young artists were unsatisfied with the conventions of painting and were looking for new forms. However,

rather than taking a roundabout way of removing frames and opening up paintings, Kazakura took "direct action" by directly attacking the contents of the tableau. In a venue littered with jumbled works of art, the empty frames left on the wall were somewhat symbolic, and Kazakura's Dadaistic spirit of directly hitting the paintings themselves with an air gun was refreshing. ${ }^{78}$

While Kosugi was stimulated by visual and plastic arts, Kazakura began to attend concerts by Kosugi's Group Ongaku. He thought that "there was a Dada spirit in Group Ongaku, because they were betting on 'time.' ... 'Time' has become a theme for me since I started getting involved in Group Ongaku." ${ }^{9}$ Invited by Sakurai Takami and his Kyūshū-ha group, they travelled together to Hakata, and Kosugi witnessed there one of the first performances with a big advertising balloon ("ad-balloon") during

77 Atsuo, "Interview with Kosugi Takehisa," 16-17.

78 Kosugi, "Chikyū no oto wo kiku," 9.

79 Kikuhata Mokuma, "Kazakura Shō Taidan - Hapunā no kiseki" [A Conversation with Kazakura Shō - The Locus of a Happener], Kikan 12 (1981): 5-32. 
the "Grand Meeting of Heroes": ${ }^{80}$ "the balloon and the performer, which had been separated until then, became one space in an instant. This subtraction of space is the quintessence of his performance of disappearing." Kosugi recalls: "Rather than sound expression, I was more interested in art as a one-time event in space, connected with action and coincidence. I think Kazakura probably started his event-like performance with the same idea." ${ }^{\prime 1}$

In 1956, Kazakura began a series of performances which shine because of their simplicity, insisting on the fact that "it was important to do something that anyone could do": ${ }^{2}$ falling from a chair, or from a ladder, walking, dropping light bulbs on a canvas, etc. ${ }^{83} \mathrm{He}$ also staged more dangerous actions that not anyone could do: standing on his head, burning his chest with an iron (and almost fainting), entering a trunk (and almost dying by asphyxia), etc. His signature performance, which he did until the 200os, uses, as mentioned, a large ad-balloon. He would, in most cases, inflate the balloon and enter it, sometimes taking with him sound devices like a harmonica, or a stick as an extension of his arms, and then move around not seeing but hearing the environment, until there was no air in the balloon anymore, getting out in time to avoid asphyxia.

Kazakura did a joint performance with Kosugi in a large bright room of the Pompidou Center (Paris) in 1986. ${ }^{84}$ Kazakura's ad-balloon was first covered with newspaper. The balloon was then inflated with air, growing from under those newspapers. Kazakura then entered the balloon and began to move around the space. The audience was sitting on the floor near the walls around the performance space. Kosugi was using his electric violin with a wireless system, and moving through the middle of the space, while Kazakura would move everywhere, including where the audience was sitting, most often with a comical effect.

Once the balloon was full of air, the newspapers had been dispersed on the floor. While playing the violin, Kosugi would walk on the newspapers, and make all kinds of sounds. He believed objects can be used in a variety

80 The event was held on November 15-16, 1962, at Momoji beach, Fukuoka.

81 Kosugi, "Chikyū no oto wo kiku," 9.

82 Kikuhata, "Kazakura Shō Taidan - Hapunā no kiseki," 18.

83 Instead of walking forward, Kazakura walked backward during an Instruction Piece by Kosugi: Theatre Music-Keep walking intently, at the performance-event Sweet 16, 1963, Sōgetsu Hall, Tokyo.

84 The performance took place on December 12 and 19, 1986, during the exhibition Japon des avant-gardes 1910-1970 (December 11, 1986-March 2, 1987). 

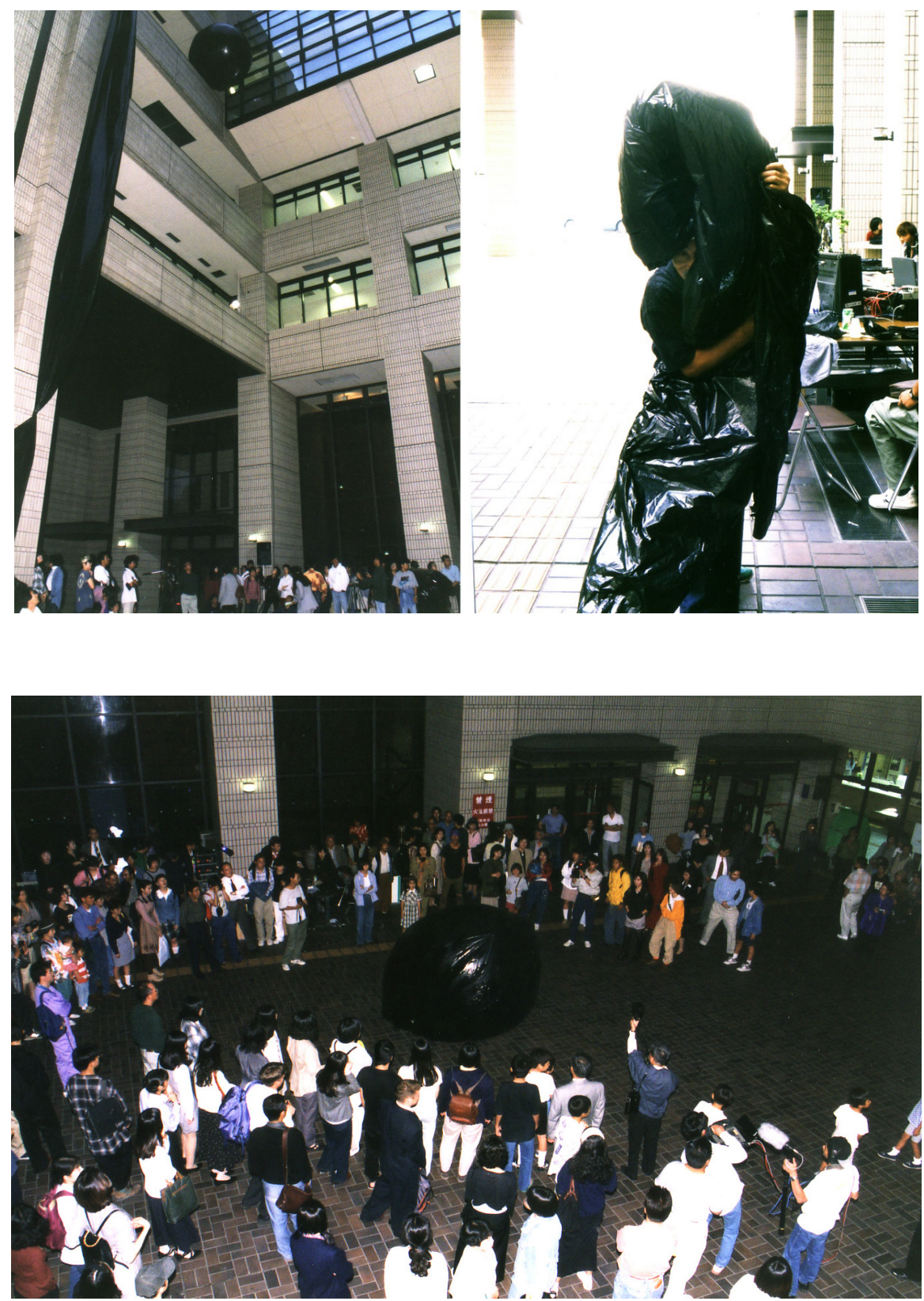

Kazakura Shō and Christophe Charles, closing performance of Taikan-on [Sound Experience], Neo Dada "Ichidanmen" (One Section) Exhibition, Ōita, Japan/Compal Hall, October 15, 1995. Top left - the black ad-balloon suspended from the ceiling; top right - "Portrait": Kazakura Shō after the performance; below - Kazakura Shō performing in the balloon. Photo credit: Endō Ritsuko. 
of manners: "If [an object] doesn't have sound that's ok too. ... This is not only sound nor action oriented, it's a combination of sound and action together." ${ }^{{ }_{85}}$ In other words, the sound is resulting from each action on each object. Sound and action are both conceived as equally important.

Moreover, objects can have several functions at once. Formerly, newspapers were not used as a sound device or a symbolic element, their use came from much more practical needs. Kazakura said about his performances in the 196os: "I often lay out newspapers on the floor. If the floor gets dirty, it's no trouble to clean it up afterwards: you just rake up the newspaper and you're done." ${ }^{\text {"6 }}$ Similarly, instruments have several functions, too. Kosugi remembers seeing a wounded piano when he visited Kazakura's home in 1985:

This legless piano was used for a performance, and then as the parts were gradually used for other works, it was finally used up and disappeared. By using a piano which was made for music (a temporal art form) in an art context (a spatial art form), the medium of the piano itself crosses the boundaries of genres. Like his balloon, the piano is used as a multidirectional potential. ${ }^{87}$

\section{Improvisation and Consciousness}

Kazakura and Kosugi also shared ideas about the "liveliness" of everyday life, and its "invisible essence." Kazakura says:

I think that creativity is rooted in our daily lives, or rather, it is something that is taken out of our daily lives. That's why I thought happenings would be closer to the essence of creativity, to extract the invisible essence of everyday life. ... I had a clear idea that I wanted to bring out the essence of it, and it became clear to me that this creation could only be said if there was life. If there is no life, there is no creation, nothing at all. So I thought that the most accurate way to create was to be on the edge of life. That's why challenging life is almost like committing suicide. ... I don't mean abandonment, I mean getting as close as possible. ${ }^{88}$

85 Hudak, "Fishing for Sound," 9.

86 Kikuhata, "Kazakura Shō Taidan - Hapunā no kiseki," 13.

87 Kosugi, "Chikyū no oto wo kiku," 10.

88 Kikuhata, "Kazakura Shō Taidan - Hapunā no kiseki," 24. 


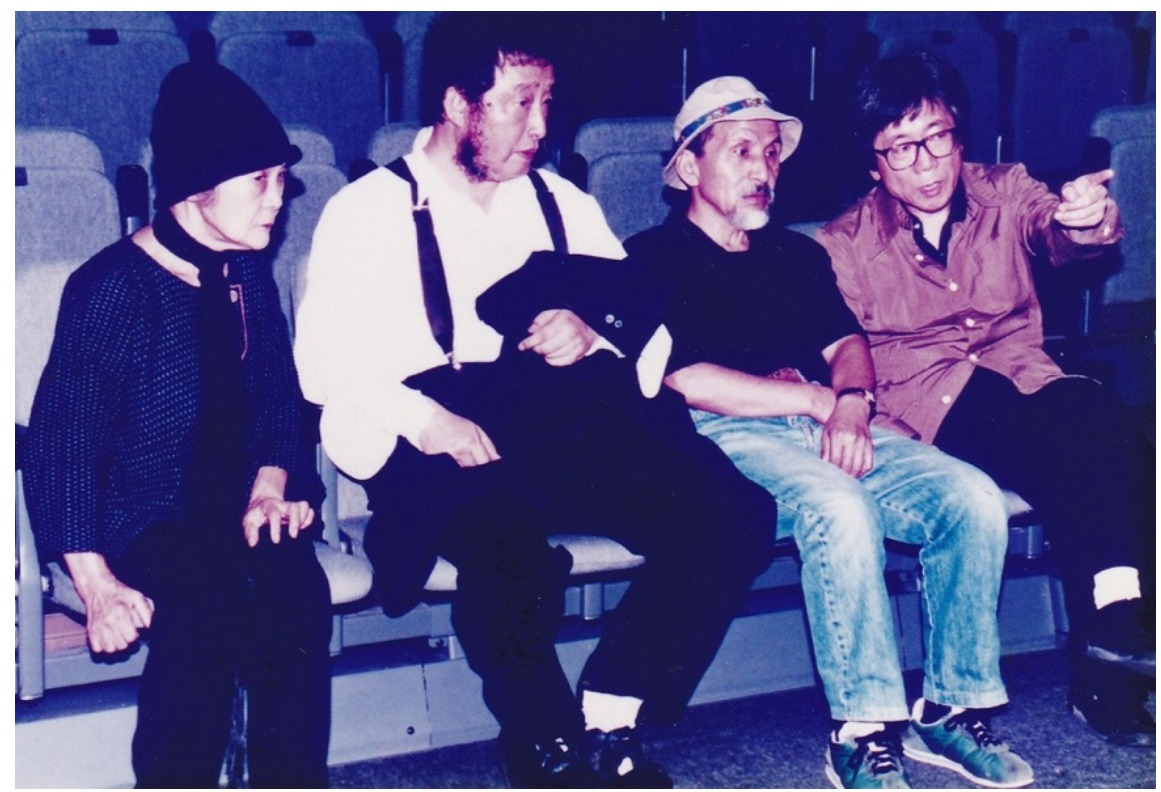

Nam June Paik Fukuoka Prize Performance, Kikyorai [Return Home], NHK Fukuoka Broadcasting Station TV Hall, 30 September, 1995. From right to left: Kosugi Takehisa, Kazakura Shō, Nam June Paik, Kuni Chiya. Photo Ishimatsu Takeo. ( Fukuoka Prize Committee. Courtesy Okamoto Takako, The Estate of Takehisa Kosugi / HEAR.

For Kosugi, "being on the edge" perhaps means constantly adapting to an environment that changes incessantly. In my 2015 interview with him in Osaka, Kosugi said:

Improvising is a means to catch what is appearing, to catch the vibrations of the universe, and to adapt to the changing environment. ... In other words, when "I" am performing, it is not only "me" who is performing. The performance is not only my own, because I am catching the environment. Because I am playing together with that environment, I am not just myself. ...

The idea of "dismantling the ego" is influenced by the specific concept of [the South Indian improvised music] Manodharma, which implies that the ego exists as a cosmic existence beyond oneself, and a musician becomes a receiver that catches that cosmic existence. Improvisation reflects changes in time, or changes in season. Music comes out through the connections between the immediate environment and what transcends the ego. It is not "my" music, but the music of a receiver that catches some presence in the universe, like a 
radio or a television. In short, a performance is something that catches the radio waves so that we can absorb them. ${ }^{89}$

Performing is not about what comes out from inside, but about catching it from outside and becoming oneself a filter, as transparent as possible. To what extent can one become selfless? Tom Johnson translates this idea as: "Kosugi continues playing his violin, or perhaps allowing the violin to play him." ${ }^{\circ}$ Even before John Cage was attracted to Eastern thought in the 1940s, some artists in the West were working in that direction: "Dada was about deconstructing, or dismantling the self, and that is also what Buddhism is all about, becoming selfless." ${ }^{\prime 1}$

\section{The Sound of the Earth}

The economy of means implies that there is room for much to happen; 433" can be considered as minimal because there is minimal action, but at the same time it is maximal because of its inclusiveness of all sounds. In their performances and happenings, Kosugi and Kazakura reveal the vibrations and changes of the environment. We might also say that they make the environment vibrate by listening to it. Kosugi remembers words by Kazakura:

"Listen to the sound of the earth." This could be taken to mean actually putting one's ear to the ground and listening, but I think this means listening to sound not as an art created by human aesthetics and purpose, such as Bach or the cello, but as a phenomenon in an unspecified and indeterminate world. It seems to me that Kazakura is saying that performance and art are about catching the phenomena that exist on the earth, that is, in everyday space, while opening our perception in all directions. ${ }^{92}$

Kazakura, wrote a poetic text about "vision" and "time" for his retrospective exhibition at the Oita Museum in 2002, which relates closely to the remarks by Kosugi and is a fitting conclusion to this essay:

89 Kosugi, interview by Charles.

90 Tom Johnson, “Takehisa Kosugi and Akio Suzuki: Stunning by Coincidence," Village Voice, April 23, 1979, 25.

91 Kosugi, interview by Charles.

92 Kosugi, "Chikyū no oto wo kiku," 10. 
Time to know,

tools and paths to know.

The path is developed,

time shrinks.

The shrunken variant of time

is negative time.

Tools left

in space,

forgotten paths and ditches.

Falling into the trenches of past cultures,

digging holes, forgetting time.

Surveying,

taking out

only the intangible,

the invisible. ${ }^{93}$

93 Kazakura, "Mirukoto no oboegaki" [Memorandum of Seeing], in Kazakura shō ten [Shō Kazakura Exhibition], ed. Kenji Ogami (Ōita: Ōita Art Museum, 2002), 12-13. 


\section{From Notes and Correspondences Regarding BUSTER, Initiating Bros (A Practice-Based Account of Work with Romeo Castellucci and Societas) Scott Gibbons}

The first notes from Romeo [Castellucci, director of Societas] arrive regarding the place where the premier will be. We have been talking about a piece entitled Bros, and Romeo conducted a workshop on some of the themes just before the pandemic struck. I review videos of the workshop and am struck by how things have changed. The room was full of people working closely together, and not a mask in sight. It's still too early for the normal venues to open safely, but there's an outdoor space in Brussels that is cleared for use by a limited number of spectators. A rather broad plaza in the open air. The city will be clearly visible all around, but at a distance. While we continue to develop Bros, we will stage the work-in-progress as BUSTER. ${ }^{94}$

The piece calls for fifty local participants who will respond to orders given uniquely to each individual via in-ear monitors. They are not actors and will not know the commands beforehand. They are dressed like old-fashioned American police, as you would see in old black-and-white silent movies.

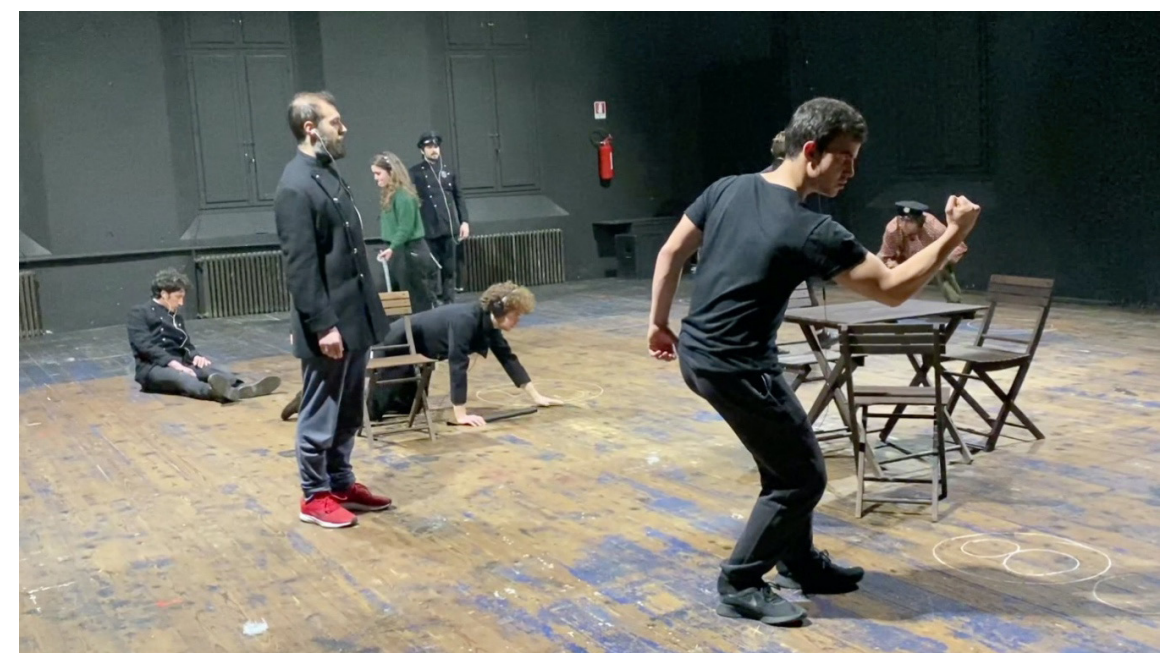

Workshop, Cesena, March 2020. Courtesy of Societas.

94 BUSTER, initiating Bros premiered May 20-24, 2021, at the Kunstenfestivaldesarts, Brussels. 
The city is female in character; however, the space where we will perform is male. (Quite literally, as we will be directly in front of the federal police headquarters with a cathedral beside!)

Two machines, seemingly military tools, ominously scan the city. A kind of sonar or radar. A small wooden statue moves its arms, raises and lowers its head, and opens its mouth wide (like a scream). A god who commands. It is placed in front of the policemen who-with their backs to the publicare in adoration of the totem.

Romeo distributes a video demonstrating the actions of the Idol; I will use this to create the sound while Istvan [Zimmermann, of Plastikart Studio] and Paolo [Cavagnolo] create the robotics.

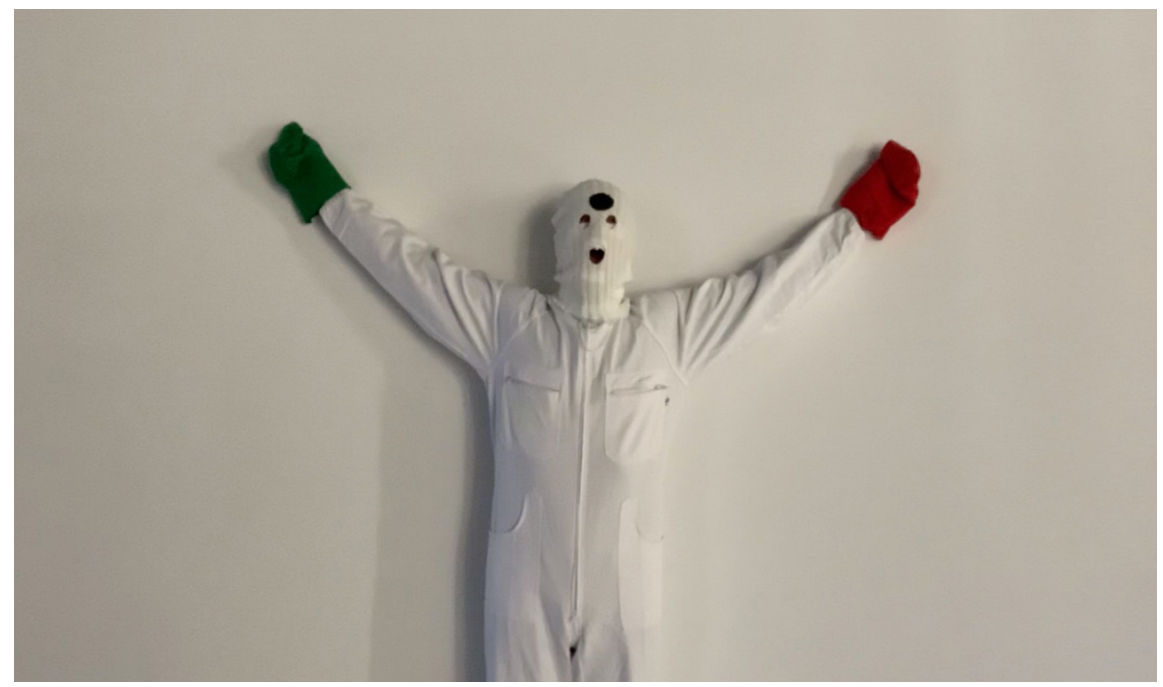

Idol reference (video still). Courtesy of Societas.

Having just cleared the woods behind my house of some pernicious and invasive holly trees, I had quite a lot of wood to rub and scrape together to create a library of sounds for the statue. Brought branches and sticks into the studio. These made good textures but were a bit too crisp. Too snappy. Went back out to collect some rotting branches that had fallen from an old oak tree. Nice and spongey, sounds like wood but a little squishy. Fleshy. After recording, had to clear the studio floor of worms and spiders. Realized the Idol's neck needed a sound that was more stiff, though. Pulled some anise from the refrigerator and tried bending a few stalks at a timethis was much more convincing. 


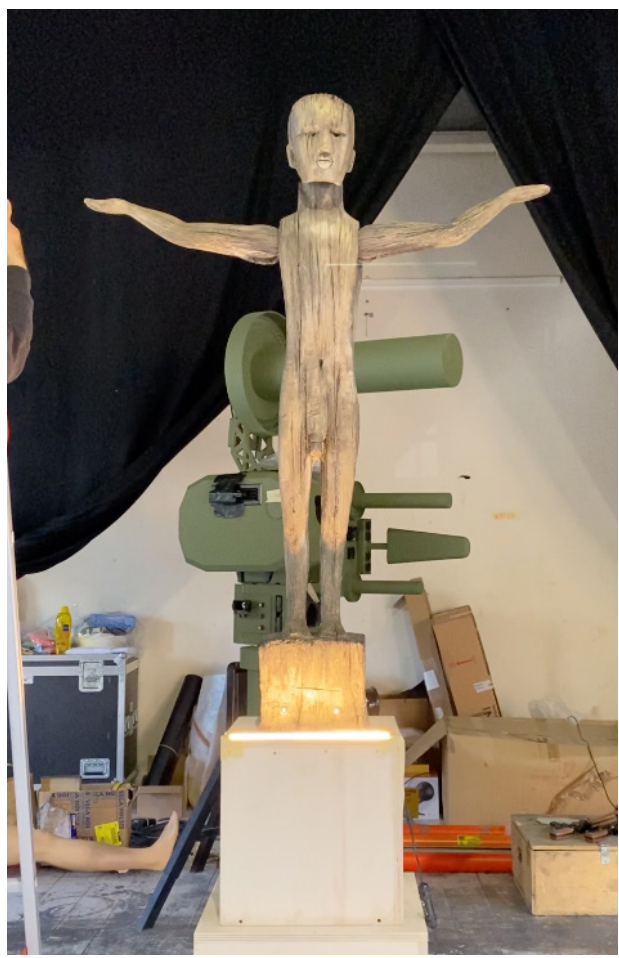

Idol reference (video still). Courtesy of Societas.
For the Idol's mouth, it needs a voice... I multi-tracked clacking wooden sticks in a sort of random percussion. Strange. Tried a deep demonic voice (layers of Latin chant in reverse), vocoded with noise to remove the tonality, but the effect was... maybe a little obvious. Tried time-stretching an infant's voice from the library. Crying, screaming. Perfect! A little voice for a little body. Granularly re-synthesized this to make it more abstract. Now it seems to be the idea of a voice, not a specific voice. The other sounds will have to be carefully placed with EQ, because this voice will be presented fullspectrum like a wall of noise.

As the Idol raises and lowers its arms, there should be a reaction from the space. Tremolo of strings, deep male voices, a precise cacophony. Each angle of the arms defined by its own narrow bandwidth (low to high).

A video of the final machine going through its choreography matches up almost perfectly with the original reference video. I have to make only a few small adjustments. I can't see the mouth when its head is hanging low, so I have to ask for another video just to verify the timing of that.

I'm not certain yet what sound(s) will work best for the two machines that scan the city, so I plan to work primarily with automation of the effects and mixer, so I can test different sounds just by dropping them into the session. The automation will force everything to sync. Romeo sends a video of the prototypes, and the effect is quite imposing. One machine has a long barrel on top, the other has a light that flashes. Both rotate independently at different rates and directions. I try close-miking some drone motors, and fine-tune the pitch and frequencies so that there are musical harmonies between the two. It's beautiful and even a little haunting, but the sound of 


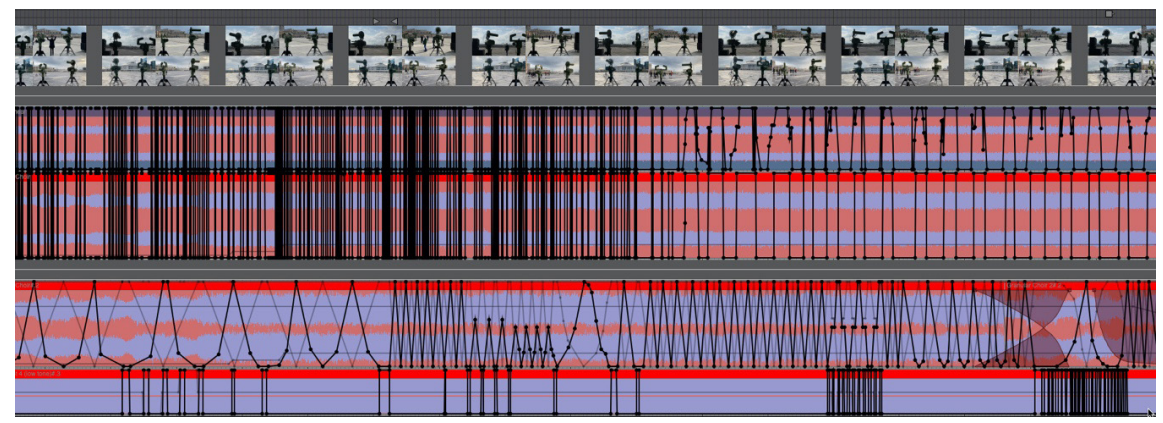

Radar project automation. Courtesy of Scott Gibbons and Societas.

the motors is too mechanical and not really organic. I tried synchronizing vocals (simple open vowels) with the light. For the other machine, the one that looks like a gun, I closely follow the video... When the barrel is scanning where the public will be, a deep scraping and grinding sound. When it points away from the public, reading the city, a sound reminiscent of sonar from a U-boat. Alternately menacing and lonely. To mark the moments when the barrel starts and stops, I look for short bursts of animal sounds in my library: a panther hissing, a rattlesnake warning... sounds that bypass the brain and register directly into the spine.

It's hard for me to see some details in the video though-I can't tell if the light is flashing when the rotating arms are oriented sideways, for example. I can sense that the rotational speed ramps up and slows down, but it's not clear where those exact moments of de/acceleration are. I ask the programmer Paolo if he can give me some details, and he soon responds with a set of text files that capture the data at $29.97 \mathrm{~Hz}$ (the sampling rate of the reference video) with an offer to interpolate the data to any rate I need. The files are a series of values, one per line, one file for each motor. I import the data to a spreadsheet and set up a new column to calculate the precise time for each change. It is impractically long; over seventeen thousand lines of data! Since the tempo in my Digital Performer project is $120 \mathrm{bpm}$ for this scene, $8 \mathrm{~Hz}$ would be a more practical sampling rate. Paolo quickly sends me a new data set at that rate, and now I can reference that for accuracy to the nearest eighth note.

I have to define the backdrop to all of these sound events. There will be the real din of the city, which is quite vital and essential, so I have to work with that without conflicting with it. I collect sirens, trains, buses, horns, pedestrians. There is a particular siren which is specific to Belgium, so I make sure 


\begin{tabular}{|c|c|c|c|c|c|c|c|c|}
\hline 1 & $\begin{array}{c}\text { A } \\
\text { MOTOR ONE }\end{array}$ & $\begin{array}{c}\text { B } \\
\text { MOTOR TWO } \\
\end{array}$ & $\begin{array}{c}\mathrm{C} \\
\text { UGHT }\end{array}$ & \begin{tabular}{l|} 
DD \\
FRAME
\end{tabular} & $\begin{array}{c}\text { E } \\
\text { TIME } \\
\end{array}$ & $\begin{array}{c}\text { F } \\
\text { MOTOR ONE }\end{array}$ & \begin{tabular}{c|} 
G \\
MOTOR TWO \\
\end{tabular} & $\begin{array}{c}\text { H } \\
\text { LGHT }\end{array}$ \\
\hline 9245 & 161 & 83 & 0 & 9244 & $5: 08$ & 160 & 80 & \\
\hline 9246 & 165 & 83 & 0 & 9245 & $5: 08$ & 160 & 80 & \\
\hline 9247 & 157 & 85 & 0 & 9246 & $5: 08$ & 150 & 80 & \\
\hline 9248 & 151 & 83 & 0 & 9247 & $5: 08$ & 150 & 80 & \\
\hline 9249 & 147 & 83 & 0 & 9248 & 5:08 & 140 & 80 & \\
\hline 9250 & 143 & 83 & 0 & 9249 & $5: 08$ & 140 & 80 & 0 \\
\hline 9251 & 137 & 85 & 0 & 9250 & 5:08 & 130 & 80 & 0 \\
\hline 9252 & 129 & 83 & 0 & 9251 & 5:08 & 120 & 80 & 0 \\
\hline 9253 & 127 & 85 & 0 & 9252 & $5: 08$ & 120 & 80 & \\
\hline 9254 & 121 & 83 & 255 & 9253 & $5: 08$ & 120 & 80 & 250 \\
\hline 9255 & 117 & 83 & 255 & 9254 & $\begin{array}{l}5: 08 \\
5: 08\end{array}$ & 110 & 80 & 250 \\
\hline 9256 & 115 & 85 & 255 & 9255 & 5:08 & 110 & 80 & 250 \\
\hline 9257 & 111 & 85 & 255 & 9256 & $5: 08$ & 110 & 80 & 250 \\
\hline 9258 & 107 & 83 & 255 & 9257 & $5: 08$ & 100 & 80 & 250 \\
\hline 9259 & 103 & 85 & 0 & 9258 & $5: 08$ & 100 & 80 & \\
\hline 9260 & 101 & 83 & 0 & 9259 & $5: 08$ & 100 & 80 & \\
\hline 9261 & $\begin{array}{r}99 \\
99\end{array}$ & 85 & 0 & 9260 & $\begin{array}{l}5.00 \\
5: 08\end{array}$ & 90 & 80 & \\
\hline 9262 & 97 & 87 & 0 & ${ }_{9261}$ & $\begin{array}{l}5.08 \\
5: 09\end{array}$ & 90 & 80 & \\
\hline 9263 & 95 & 85 & 255 & 9262 & 5:09 & 90 & 80 & 250 \\
\hline 9264 & 91 & 83 & 255 & 9263 & 5:09 & 90 & 80 & 250 \\
\hline 9265 & 91 & 83 & 255 & 9264 & 5:09 & 90 & 80 & 250 \\
\hline 9266 & 91 & 85 & 255 & 9265 & 5:09 & 90 & 80 & 250 \\
\hline 9267 & 85 & 83 & 255 & 9266 & 5:09 & 80 & 80 & 250 \\
\hline 9268 & 87 & 83 & 255 & 9267 & $\begin{array}{l}5.099 \\
5: 09\end{array}$ & 80 & 80 & 250 \\
\hline 9269 & 87 & 83 & 255 & 9268 & $5: 09$ & 80 & 80 & 250 \\
\hline 9270 & 85 & 85 & 255 & 9269 & $5: 09$ & 80 & 80 & 250 \\
\hline 9271 & 85 & 85 & 255 & 9270 & $5: 09$ & 80 & 80 & 250 \\
\hline 9272 & 81 & 85 & 255 & 9271 & 5:09 & 80 & 80 & 250 \\
\hline 9273 & 81 & 83 & 255 & 9272 & 5:09 & 80 & 80 & 250 \\
\hline 9274 & 89 & 85 & 255 & 9273 & $5: 09$ & 80 & 80 & 250 \\
\hline 9275 & 79 & 85 & 255 & 9274 & $5: 09$ & 70 & 80 & 250 \\
\hline 9276 & 79 & 83 & 255 & 9275 & $5: 09$ & 70 & 80 & 250 \\
\hline 9277 & 75 & 83 & 255 & 9276 & $5: 09$ & 70 & 80 & 250 \\
\hline 9278 & 79 & 87 & 255 & 9277 & $5: 09$ & 70 & 80 & 250 \\
\hline 9279 & 77 & 83 & 255 & 9278 & $5: 09$ & 70 & 80 & 250 \\
\hline 9280 & 77 & 79 & $\begin{array}{l}253 \\
255\end{array}$ & $\begin{array}{r}2718 \\
9279\end{array}$ & $\begin{array}{l}5: 09 \\
5: 09\end{array}$ & 70 & 70 & $\begin{array}{l}250 \\
250\end{array}$ \\
\hline 9281 & 75 & 85 & 255 & 9280 & $5: 09$ & 70 & 80 & 250 \\
\hline 9282 & 77 & 83 & 0 & 9281 & $5: 09$ & 70 & 80 & \\
\hline 9283 & 75 & 83 & 0 & 9282 & $5: 09$ & 70 & 80 & 0 \\
\hline 9284 & 71 & 83 & 0 & 9283 & 5:09 & 70 & 80 & \\
\hline 9285 & 75 & 83 & 0 & 9284 & $5: 09$ & 70 & 80 & \\
\hline 9283 & 75 & 85 & 0 & 9285 & $5: 09$ & 70 & 80 & 0 \\
\hline 9287 & 75 & 83 & 0 & 9286 & $5: 09$ & 70 & 80 & 0 \\
\hline 9288 & 75 & 83 & 0 & 9287 & $5: 09$ & 70 & 80 & 0 \\
\hline 9289 & 75 & 85 & 0 & 9288 & $5: 09$ & 70 & 80 & 0 \\
\hline 9290 & 77 & 85 & 0 & 9289 & $5: 09$ & 70 & 80 & 0 \\
\hline 9291 & 73 & 83 & 0 & 9290 & $5: 09$ & 70 & 80 & 0 \\
\hline 9292 & 75 & 89 & 0 & 9291 & $5: 10$ & 70 & 80 & 0 \\
\hline 9293 & 73 & 83 & 0 & 9292 & $5: 10$ & 70 & 80 & 0 \\
\hline 9294 & 73 & 85 & 0 & 9293 & $5: 10$ & 70 & 80 & 0 \\
\hline 9295 & 73 & 85 & 0 & 9294 & $5: 10$ & 70 & 80 & \\
\hline 9296 & 71 & 85 & 0 & 9295 & $5: 10$ & 70 & 80 & \\
\hline
\end{tabular}

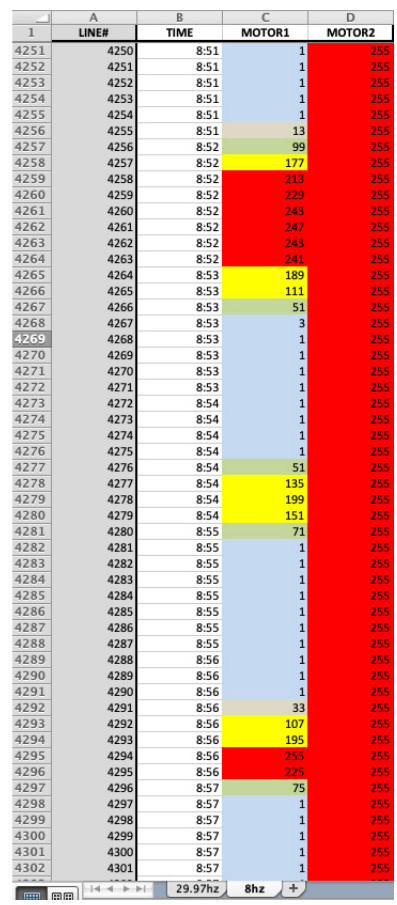

Left: Radar motors data at 29.97hz. Right: Radar motors data at 8hz. Courtesy of Scott Gibbons and Societas.

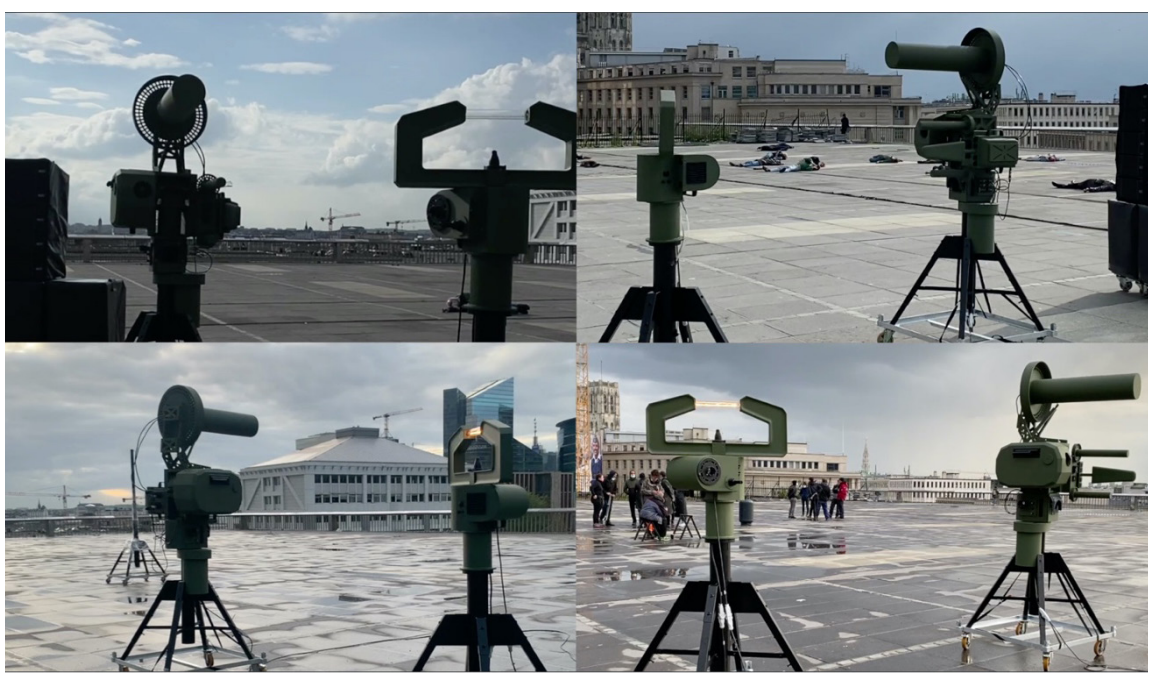

Montage of radars. Courtesy of Societas. 
to use that. I discover that layering many, many, many car/truck/bus horns in harmony gives an effect like a giant organ. I make a quick demo of a crescendo with this effect and put that in reserve. It takes a while to assemble, but I want the sirens to turn into the voices of a woman crying, sobbing. The occasional honking horn makes a nice connection to the image of the gun, I think, which can perhaps be a tuba, or some kind of military shofar from the 1950s. A little tremolo and delay to give it some shimmer and musicality.

Many small details require some simple foley. Shortwave radio, an old telephone, magnesium camera flashbulbs... Claudio [Tortorici] is the sound tech on site, and he will have to experiment with the placement of these sounds in the actual space. I give him sound files that are as dry and neutral as possible. Romeo sends some recordings from the site that need a little restoration work, these are nice little tasks that are welcome when I need a break from working on the heavier scenes.

The company arrives in Brussels to begin rehearsals. COVID restrictions mean I'm not able to be present on-site, but we all have strong internet connections to share materials. I'm happy at least to be able to use the hardware and space in my studio to record, instead of being restricted to my laptop in a hotel room.

Romeo reports that the urban soundscape I had prepared sounds too authentic in the space. I prepare and send some variations using bandpassed delays and time stretching to impart a more dream-like sensation of a memory of the city.

I receive more videos of the machines once they're installed on site and discover-with dismay-that the position of the radar gun varies enough to make my earlier approach inutile. Even though the machines may begin from the exact same orientation, there is a gradual drift over time, and even halfway through the sequence they may all be pointing in completely different directions. I confirm with Paolo that the commands sent to the motors only regulate the rotational speed. The machines would need to have positional sensors to follow the same path each time. This is possible in the future but not now. The premiere is only a few days away at this point, so I need to create something quickly that follows the movement, but not the direction. Hmm. The sounds I used before won't be effective anymore, so I need a fresh new palette. I want to tie back to the soundscape of the city, so maybe this radar machine can have a voice not unlike the car horns. Tuba, alpenhorn, didgeridoo.

In Final Cut I've created a montage of the machines going through their sequences simultaneously. While watching that, I record several passes of 
performances using horn patches. I identify and comp my favorite voices and moments, and then go back to automate the finer details. I really miss the threatening sensation when the machine's "eye" looks across me, but this new approach has a cinematic quality which I think will be quite useful outside in the open, under the night sky. Anyway, there's no more time so it has to work for now.

Romeo reports that the Idol sequence is generally working very well on site, except that it wants a climax. I remember the sound of the "organ crescendo" constructed with horns. That might work here... It was only sixty seconds long, though. I don't feel that I have a proper sense of the passing of time from watching disjointed videos on my monitor, so I re-create longer and shorter variations and send them for testing in rehearsals.

The evening of the debut arrives. By late morning on the West Coast, I start to see some text messages coming in from Brussels, all very happy and relieved. There is a sync problem with the radar machines, but otherwise everything is working well. Despite the enthusiasm, I take this as very mixed news. I wonder if the Arduino is playing back at $48 \mathrm{kHz}$ instead of $44.1 \mathrm{kHz}$. It must be something simple like that. We have some time before the next phase-Bros-to address the problem. Anyway, much will assuredly need to change as we consider how to migrate from a large outdoor space back to an indoor space. I change the title of my To-Do list, from "BUSTER | to do" to "Bros | to do." 


\section{Works cited}

\section{Performances and recordings cited}

Abela, Lucas (pseud. Justice Yeldham). "Lucas 'Granpa' Abela Live.' Recorded live at cave12, Geneva, February 21, 2016. Uploaded on YouTube, June 4, 2016. https://www. youtube. $\operatorname{com} /$ watch $? \mathrm{v}=2 \mathrm{aMBMbEWc6I}$. Graphic content warning.

ASUNA (Asuna Arashi), 100 Keyboards. 2014. Video excerpts from the live installation of "ASUNA: One Day Exhibition," Gallery Kapo, Kanazawa, July 2016. https:// www.youtube.com/watch?v=Vh3 H6x1GFn4.

Blamey, Peter. Double Partial Eclipse. 2014. Performance for video presented as part of Material Sound at Home, curated by Caleb Kelly, Black Mountain College Museum + Arts Center, Asheville, NC, May 2020. Uploaded May 21, 2020. https://vimeo. com/421135001.

\section{_. Forage. Sydney, April 2012.}

_. Invisible Residue. Digital album. Recorded in Sydney, March-May, 2015. Released on Bandcamp, May 8, 2020. https:// peterblamey.bandcamp.com/album/invisible-residue-2.

\section{- Rare Earth Orbits. Digital album. Re- corded January-March, 2020. Released on Bandcamp, May 3, 2020. https://peterblamey. bandcamp.com/album/rare-earth-orbits. \\ Branch Nebula. Crush. Sydney Opera House, November 18-22, 2020.}

—. High Performance Packing Tape. Liveworks Festival of Experimental Art, Carriageworks, Eveleigh, Sydney, October 24-27, 2018.

Castellucci, Romeo. BUSTER, initiating Bros. Societas production. Music by Scott Gibbons. Kunstenfestivaldesarts, Brussels, May 20-24, 2021.
Fox, Robin. Diaspora: A Science Fiction Revelation. Melbourne Festival, The Substation, October 3-6, 2019.

Goebbels, Heiner. Black on White. Originally created in 1996 as Schwarz auf Weiss. Adelaide Festival, March 12-14, 1998.

- Stifters Dinge: A Performative Installation. Théâtre Vidy, Lausanne, September 10-28, 2007.

Hinde, Kathy. Piano Migrations. Version II. Concrete \& Glass Festival, Hoxton, London, May 20-27, 2010.

River Traces 1. Digital online version, Distant Arcades, MUTEK Montréal, September $8-20,2020.16 \mathrm{~mm}$ projection with live mixed sound, Bristol Experimental Expanded Film, Centre of Gravity Exhibition, October 2020.

—. Tipping Point. Norfolk \& Norwich Festival, May 9-10, 2014.

\section{- Twittering Machines - Live AV. MUTEK Montréal, August 2019.}

Hope, Cat. Speechless. Perth Festival, Sunset Heritage Precinct, February 26-March 3, 2019.

Kazakura, Shō and Christophe Charles. Taikan-on [Sound Experience]. Neo Dada "Ichidanmen" Exhibition, Ōita, Japan/ Compal Hall, October 15, 1995.

Kazakura, Shō and Kosugi Takehisa. Performance at the exhibition Japon des avant-gardes 1910-1970 (December 11, 1986-March 2, 1987). Centre Georges-Pompidou, Paris, December 12 and 19, 1986.

Kosugi, Takehisa. Theatre Music-Keep walking intently. Sōgetsu Hall, Tokyo, 1963.

Pelusio, Michela. SpaceTime Helix. 2012. Performance at Sonica Festival, Tramway, Glasgow, November 2, 2019. 
Priest, Gail, and Thomas Burless. A Continuous Self-Vibrating Region of Intensities. Retitled in 2021 as We Are Oscillators. Liveworks Festival of Experimental Art, Track 12, Carriageworks, Eveleigh, Sydney, October 23-26, 2019.

Saulwick, Tamara. Endings. 2015-18. Radio adaption of Endings by Tamara Saulwick and Peter Knight, in consultation with Miyuki Jokiranta, ABC Radio National, 2017. http:// www.abc.net.au/radionational/programs/ soundproof/endings/8188440.

. Pin Drop. 2010-14. Radio adaptation by Saulwick and Peter Knight, ABC Radio National, 2013. https://soundcloud.com/tamara-saulwick/pin-drop-radio-adaptation.

Schack-Arnott, Matthias. Anicca. Season 2, Arts House, Melbourne, November 2-6, 2016.

.Everywhen. Melbourne International Arts Festival, The Substation, October 10-13, 2019.

Speak Percussion (Eugene Ughetti, composer). Polar Force. Arts Centre, Melbourne, November 24-December 1, 2018.

(Eugene Ughetti and Robin Fox, composers). Transducer. Totally Huge New Music Festival, Hacket Hall, Western Australian Museum, Perth, August 10, 2013.

Umeda, Tetsuya. Things That Don't Know/ Ringo. Sapporo International Art Festival, August 6-October 1, 2017.

Varchausky, Nicolás. Mesa de Dinero [Money Desk]. 2018. Performance at Sonica Festival, The Art School, Glasgow, November 2, 2019.

\section{Literature cited}

Barad, Karen. "Diffracting Diffraction: Cutting Together-Apart." Parallax 20, no. 3 (2014): 168-87.

Cage, John, and Daniel Charles. For the Birds. Boston: Marion Boyars, 1981.
Charles, Daniel. "Music and Antimetaphor." In Musical Signification: Essays in the Semiotic Theory and Analysis of Music, edited by Eero Tarasti, 27-42. Berlin: De Gruyter Mouton, 1995.

Egan, Greg. Diaspora. London: Millennium, 1997.

Goebbels, Heiner. "The Sounds of Things." In Sonic Thinking: A Media Philosophical Approach, edited by Bernd Herzogenrath, 87-97. New York: Bloomsbury, 2017.

Haraway, Donna. "Situated Knowledges: The Science Question in Feminism and the Privilege of Partial Perspective." Feminist Studies 14, no. 3 (1988): 575-99.

Herzog, Werner. Scenarios, translated by Martje Herzog and Alan Greenberg. Minneapolis: University of Minnesota Press, 2017.

Hudak, John. "Fishing for Sound: An Interview with Takehisa Kosugi (1990)." In Takehisa Kosugi Interspersions, edited by René Block, 7-12. Berlin: daadgalerie, 1992. Exhibition catalog.

Kahn, Douglas. "The Latest: Fluxus and $\mathrm{Mu}$ sic." In Sound, edited by Caleb Kelly, 28-42. Cambridge, MA: MIT Press, 2011.

Kazakura, Shō. "Mirukoto no oboegaki" [Memorandum of Seeing]. In Kazakura shō ten [Shō Kazakura Exhibition], edited by Kenji Ogami, 12-13. Ōita: Ōita Art Museum, 2002.

Kelly, Caleb. "Materials of Sound: Sound As (More Than) Sound." Journal of Sonic Studies 16 (2018). https://www.researchcatalogue. net/view/456784/456785/o/o.

Kikuhata, Mokuma. "Kazakura Shō Taidan - Hapunā no kiseki” [A Conversation with Kazakura Shō - The Locus of a Happener]. Kikan 12 (1981): 5-32.

Kōji, Kawasaki. “Takehisa Kosugi no ongaku" [The Music of Kosugi Takehisa]. In Ongaku no pikunikku, [Music Picnic], 201-14. 
Ashiya City: Ashiya City Museum of Art and History, 2017. Exhibition catalog.

Kosugi, Takehisa. "Chikyū no oto wo kiku" [Listen to the Sound of the Earth]. In $\mathrm{Ka}$ zakura shō ten [Shō Kazakura Exhibition], edited by Kenji Ogami, 8-10. Ōita: Ōita Art Museum, 2002.

LaBelle, Brandon. Background Noise: Perspectives on Sound Art. New York: Continuum, 2006.

Paik, Nam June. "Sekai de mottomo mumei na yūmeijin" [The World's Most Obscure Celebrity]. In Tokei no furiko, Kazakura Shō [Clock Pendulum, Kazakura Shō], 8-9. Kagawa: Sano Garō, 1996.

Priest, Gail. "The Now of History: Tomographic and Ficto-Critical Approaches to Writing About Sonic Art." RE:SOUND 2019, Eight International Conference on Me- dia Art, Science, and Technology, Aalborg, Denmark, 20-23 August, 2019. https://www. doi.org/10.14236/ewic/RESOUND19.9.

Suga, Akira. "Nichijō no Minaoshi" [Reconsideration of the Everyday]. In Neo-Dada Japan 1958-1998 - Arata Isozaki and the Artists of the "White House," 150-59. Öita: Ōita City Board of Education, 1998.

Wolff, Christian. "On Form." In FormSpace. Die Reihe 7, 26-31. Bryn Mawr: Theodore Presser, 1965.

Yamamoto, Atsuo. "Interview with Kosugi Takehisa." In Takehisa Kosugi: World of Sound, New Summer, 2-27. Ashiya City: Ashiya City Museum of Art and History, 1996. Exhibition catalog.

Christophe Charles born 1964 in Marseille (France), has been living in Japan since 1987. He participated in a performance workshop by Kosugi Takehisa at Les Fêtes musicales de la Sainte-Baume (France) in 1979, and attended a joint performance by Kosugi and Kazakura Shō at Pompidou Center (Paris) in 1986. He has performed electronic music with Kazakura eight times between 1992 and 1995 in Europe and Japan. Charles wrote a PhD dissertation about Video Art in Japan (Tsukuba University, 1996; INALCO Paris, 1997) and is now professor at the Department of Imaging Arts and Sciences, Musashino Art University, Tokyo.

Scott Gibbons is an American-born composer and performer of electroacoustic music. His work is notable for its rigorous use of single and unexpected objects as sole instrumentation. For example, Unheard: Sonic arrangements from the microcosmos, which uses only sounds recorded at the molecular level; and music for the 12oth anniversary of the Eiffel Tower which incorporated sounds of the tower itself played as percussion. His work with Romeo Castellucci and Societas (Genesi: From the Museum of Sleep, Tragedia Endogonidia, Inferno) demonstrates an acute balance between delicacy and physicality, often focusing on frequencies that are at the outermost limits of human hearing.

Cat Hope is a composer, sound artist, performer, songwriter, and noise artist. She is a classically trained flautist, self-taught vocalist, experimental bassist, and is the director of Decibel new music ensemble. Her music is conceptually driven, using animated graphic scores, acoustic/electronic combinations and score reading technologies. Her music has been discussed in books such as Hidden Alliances (Schimana, 2019), Sonic Writing (Magnusson, 2019), Loading the Silence (Kouvaras, 2013), Women of Note (Appleby, 2012), Sounding Post- 
modernism (Bennett, 2008) as well as periodicals such as Gramophone, The Wire, Limelight, and Neue Zeitschrift für Musik. In 2011 and 2014 she won the Award for Excellence in Experimental Music at the Australian Art Music Awards, and her opera Speechless won the Best New Dramatic Work category in 2020. Her music has been played around the world, and she is a Professor of Music at Monash University, Melbourne, Australia.

Gail Priest lives on the land of the Darug and Gundungurra people now known as Katoomba (Australia). Her practice encompasses performance, recording, installation, curation, and writing. She has performed and exhibited nationally and internationally presenting work in the UK, Iceland, France, Germany, Italy, Slovenia, Norway, Hong Kong, and Japan. Originally trained in theater, she has worked as a sound designer/composer collaborating with independent directors and choreographers. Also instigating her own sound theater work she has created One thing follows another, in collaboration with choreographer Jane McKernan, an exploration of Fluxus strategies in the twenty-first century; and We are Oscillators, in collaboration with designer Thomas Burless, exploring vocal cymatics, both works presented by Performance Space, Sydney. She has written extensively about sound and media art and was Associate Editor/Online Producer for the Australian arts magazine RealTime (2003-2015). She was also the editor of the book Experimental Music: Audio Explorations in Australia (UNSW Press, 2009). She is nearing completion of a $\mathrm{PhD}$ at the University of Technology, Sydney, exploring ficto-critical writing strategies in digital sound studies.

Matthew Sergeant is a composer/researcher whose work is currently exploring ideas surrounding materials, materiality, and the relationships between human and nonhuman things. His creative work is frequently performed internationally, both throughout the Europe, North, Central, and South America, Asia, and Australasia. His music has been commissioned and/or performed by internationally acclaimed ensembles, including the London Symphony Orchestra (UK), the BBC Concert Orchestra (UK), the BBC Singers (UK), CEPROMusic (Mexico), The House of Bedlam (UK), BCMG (UK), Divertimento Ensemble (Italy), ELISION Ensemble (Australia), ensemble 10/10 (UK), ensemble plus-minus (UK), EXAUDI (UK) and the Nieuw Ensemble (Netherlands), as well as numerous ongoing creative partnerships with emerging and established soloists. Matthew's research is widely published, and he is currently working on edited collections for Boydell \& Brewer and Cambridge Scholars Publishing. He is currently Reader in Music at Bath Spa University. 